\title{
Influences of Orography and Coastal Geometry on a Transverse-Mode Sea-Effect Snowstorm over Hokkaido Island, Japan
}

\author{
LEAH S. CAMPBELL ${ }^{\mathrm{a}}$ AND W. JAMES STEENBURGH \\ Department of Atmospheric Sciences, University of Utah, Salt Lake City, Utah \\ YOSHINORI YAMADA \\ Meteorological Research Institute, Japan Meteorological Agency, Ibaraki, Japan \\ MASAYUKI KAWASHIMA AND YASUSHI FUJIYOSHI \\ Institute of Low Temperature Science, Hokkaido University, Sapporo, Japan
}

(Manuscript received 29 September 2017, in final form 24 April 2018)

\begin{abstract}
Sea-effect snowstorms generated over the Sea of Japan produce consistent and often heavy snowfall throughout the winter season, impacting downstream communities in northern and central Japan. Here, we use observations and Weather Research and Forecasting (WRF) Model simulations to examine the precipitation distribution produced by transverse-mode sea-effect snowbands that interacted with the mountainous terrain circumscribing Ishikari Bay, Hokkaido Island, Japan, on 12 January 2014. The bands observed here were horizontal convective rolls aligned normal to the mean flow and were $\sim 10 \mathrm{~km}$ wide and up to $\sim 100 \mathrm{~km}$ long. The bands approached Ishikari Bay at intervals of $\sim 10-16 \mathrm{~min}$, intensifying as they progressed through a quasi-stationary, elongated enhancement region that paralleled the Shakotan Peninsula and extended into the Ishikari plain. Hydrometeor advection, through an ascent region over the northeast slope of the Shakotan Peninsula, and along clockwise-turning trajectories steered by the boundary layer directional shear, contributed to sustained precipitation enhancement along a curve in the elongated enhancement region near the entrance to Ishikari Bay. Downstream, orographic flow deflection by the coastal mountains, likely accentuated by thermal and roughness gradients along the Shakotan Peninsula's shoreline, produced convergence and ascent along the elongated enhancement region. This study demonstrates the impact of downstream topography on sea-effect snowstorms and has implications for improving the prediction of snowfall in this and other lake- and sea-effect regions.
\end{abstract}

\section{Introduction}

Sea- and lake-effect snowstorms impact urban and rural communities with intense, continuous, and often extremely localized snowfall (e.g., Magono et al. 1966; Niziol et al. 1995; Eito et al. 2005; Laird et al. 2009; Kristovich et al. 2017). Nearly omnipresent sea-effect snowfall generated over the Sea of Japan affects western Japan during the Asian winter monsoon (see Fig. 1 for geographic references), producing mean annual snowfall

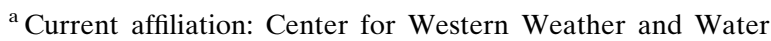
Extremes, Scripps Institution of Oceanography, University of California, San Diego, La Jolla, California.
}

Corresponding author: Leah S. Campbell, 11campbell@ucsd.edu accumulations as high as $600 \mathrm{~cm}$ in Sapporo on Hokkaido Island (population 1.9 million) and $760 \mathrm{~cm}$ in Aomori on Honshu Island (population 300000; Steenburgh 2014). Some of the deepest seasonal snowpacks in the world are found in the mountains of western Japan, with average annual snow depths as high as $6.6 \mathrm{~m}$ at $1205 \mathrm{~m}$ MSL (Yamaguchi et al. 2011). Gaining a better understanding of the mechanisms controlling the intensity and distribution of sea- and lake-effect snowstorms in Japan and around the world is important to improve winter storm forecasts of these frequently impactful events (e.g., Niziol 1987; Kristovich et al. 2017) and has implications for improving seasonal runoff predictions (e.g., Ellis and Johnson 2004) and projections of climate change impacts on snow and freshwater resources (e.g., Kawase et al. 2013; Notaro et al. 2015). 

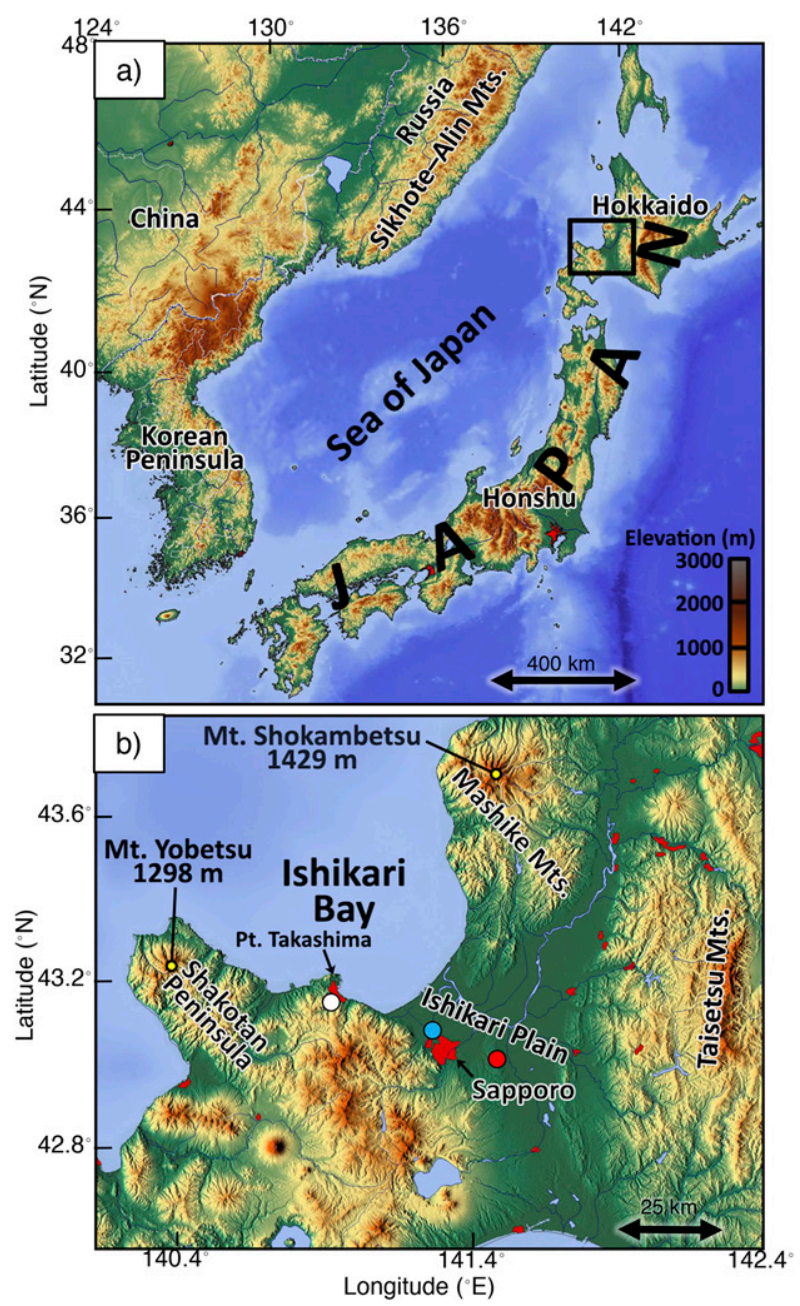

FIG. 1. Topography of (a) East Asia and Japan and (b) western Hokkaido. Terrain elevation ( $\mathrm{m} \mathrm{MSL}$ ) color filled as in scale in (a). Black box in (a) represents location of (b). Red color fill represents urban areas. White dot represents location of the Sapporo radar, cyan dot the ILTS meteorological station, and red dot the Kitahiroshima radar. Adapted from maps-for-free.com.

When a cold, continental air mass flows over a relatively warm body of water such as the Sea of Japan or the Great Lakes of North America, sensible and latent heat fluxes from the water surface warm, moisten, and destabilize the atmosphere, producing moist convection that typically extends upward to a capping inversion or stable layer at the top of the boundary layer (e.g., Tsuchiya and Fujita 1967; Niziol 1987; Byrd et al. 1991; Chang and Braham 1991). Over larger bodies of water such as the Sea of Japan, or when the prevailing boundary layer flow is oriented across the short axis of an elongated body of water, sea- or lake-effect convection frequently organizes into horizontal roll clouds oriented parallel to the prevailing flow (e.g., Asai 1970; Kelly 1982, 1984; Kristovich 1993). Such bands, which

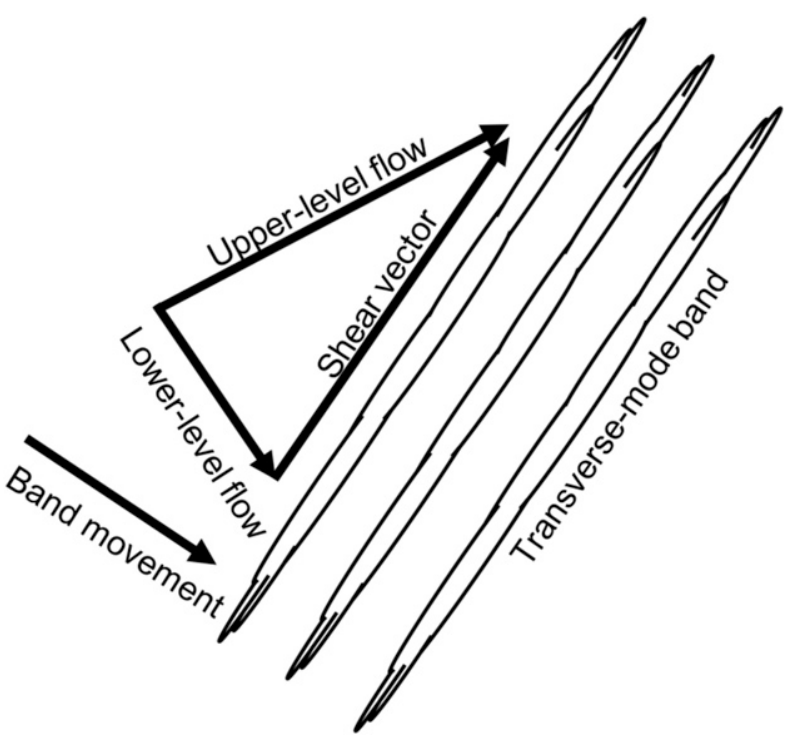

FIG. 2. Conceptual diagram of the relationship between boundary layer winds and transverse-mode bands. Based on Fig. 4 of Asai (1972).

are favored by weak directional boundary layer shear, are referred to as longitudinal-mode (L mode) bands in the Japanese literature (e.g., Miura 1986; Yamada et al. 2010). Stronger, quasi-stationary, flow-parallel snowbands form in the lee of isolated topographic obstacles or downstream of concavities in the upstream coast due to terrain- and thermally driven convergence. Two areas of such convergence frequently produce these bands over the Sea of Japan. The first, known as the Japan Sea polar airmass convergence zone (JPCZ), forms downstream of the shoreline concavity where the Korean Peninsula joins the Eurasian coast and impacts Honshu Island (e.g., Hozumi and Magono 1984; Ohigashi and Tsuboki 2007). The second forms in response to convergence in the lee of terrain complexities in the Sikhote-Alin range and extends downstream to Hokkaido Island (e.g., Katsumata et al. 1998; Ohtake et al. 2009).

A less-studied phenomenon over the Sea of Japan is transverse-mode (T mode) snowbands, which accounted for $\sim 12 \%$ of observed sea-effect precipitation in a 1-yr study along Honshu's west coast (Nakai et al. 2005). Transverse-mode bands are quasi-periodic convective rolls that align parallel to the shear vector and roughly perpendicular to the mean flow during periods of strong boundary layer directional shear (Fig. 2). Tsuchiya and Fujita (1967) first described transverse-mode bands, including their landfall and movement through the valleys of Honshu, while Asai (1972) provides an overview of the band dynamics. Although this morphology is mentioned frequently 
in the Japanese literature (e.g., Murakami et al. 2003; Nakai et al. 2003, 2005) and transverse-mode structure and formation mechanisms were examined in more detail by Eito et al. (2010), few studies have examined the precipitation distributions produced by these bands or their structure, occurrence, and evolution as they make landfall.

The topography of Japan's mountainous and relatively densely populated west coast profoundly shapes the distribution of precipitation produced by landfalling seaeffect snowstorms (e.g., Murakami et al. 1994; Nakai and Endoh 1995). These snowstorms frequently occur in the absence of synoptically forced precipitation and therefore are susceptible to mesoscale influences, such as shoreline geometry, thermally driven wind circulations, orographic channeling of flow, and the enhancement of precipitation over coastal terrain.

Previous studies have identified a number of mechanisms that may contribute to the orographic modification of sea- and lake-effect precipitation systems, such as the seeder-feeder effect (Murakami et al. 1994; Nakai and Endoh 1995), increased ice nucleation over the terrain (Saito et al. 1996), hydrometeor transport from overwater ascent maxima to downstream terrain (e.g., Alcott and Steenburgh 2013; Campbell and Steenburgh 2017), particle sorting (Magono et al. 1966; Harimaya and Sato 1992; Harimaya and Kanemura 1995), and subcloud sublimation (Murakami et al. 1994; Campbell and Steenburgh 2017). In some cases, orographic lift can deepen the boundary layer and invigorate convection, as has been suggested in some studies of sea effect in Japan (Nakai et al. 1990; Saito et al. 1996). In contrast, Minder et al. (2015) found that over the more modest Tug Hill Plateau, downstream of Lake Ontario, most storms become shallower and undergo a convective-to-stratiform transition. Precipitation enhancement may also be produced by nonorographic factors, such as interactions of the incipient flow with land-breeze fronts, katabatic winds, or complexities in the downstream shoreline (e.g., Tsuboki et al. 1989; Tachibana 1995; Steenburgh and Campbell 2017).

Here, we focus on the interactions of a sea-effect snowstorm with the complex topography of Japan's northernmost major island, Hokkaido (Fig. 1). On Hokkaido, frequent snowfall is generated over the northern Sea of Japan (a fetch of $\sim 350-400 \mathrm{~km}$ in northwesterly flow) during the months of December, January, and February. Sea-effect snowstorms impact coastal terrain features, such as the mountains of the Shakotan Peninsula (1000-1300 m MSL), the Mashike Mountains (1000-1500 m MSL), and the larger, inland Taisetsu Mountains (1900-2100 m MSL). These three mountain ranges, made up of numerous, cone-shaped volcanic peaks, surround the expansive Ishikari plain, which extends east toward the Taisetsu Mountains from Ishikari Bay and is home to the metropolis of Sapporo.

Hokkaido's coastal topography creates poorly understood, three-dimensional interactions with sea-effect snowfall that make accurate forecasting of precipitation distribution and amount difficult. For example, the mountains of the Shakotan Peninsula can act as a barrier to the incoming northerly-to-northwesterly flow of the winter monsoon, deflecting and channeling flow into the Ishikari plain (Kikuchi et al. 1987), an effect that has also been observed along the coast of the Hokuriku region of Honshu (Yoshihara et al. 2004). Additionally, convergence in the lee of the coastal peaks around Ishikari Bay sometimes forms quasi-stationary snowbands that affect the Ishikari plain (Kikuchi et al. 1987; Fujiyoshi et al. 1992). Given the multifaceted nature of orographic effects in the region, the accurate forecasting of snowfall timing and distribution is often difficult.

We specifically examine a sea-effect snowstorm that impacted Hokkaido Island on 12 January 2014 (all subsequent years are 2014 unless otherwise stated), focusing on a 6-h period (0320-0920 UTC 12 January) when transverse-mode snowbands impacted the Ishikari Bay region of Hokkaido's western coast. Of particular interest is the formation and maintenance of a quasistationary, elongated region of precipitation enhancement, oriented parallel to the Shakotan Peninsula but orthogonal to the transverse-mode snowbands that progressed through it, that extended over Ishikari Bay and into the Ishikari plain. We use radar observations from the region and Weather Research and Forecasting (WRF) Model simulations of the event to analyze the mechanisms that produced the observed distribution of snowfall. We present our data and methods in section 2, an overview of the event and the observed reflectivity structures around Ishikari Bay in sections 3 and 4, model validation in section 5 , and an investigation of the mechanisms producing these structures in sections 6 and 7 . Discussion, conclusions, and future work are presented in section 8 .

\section{Data and methods}

\section{a. Observational data and analyses}

To describe the broader synoptic context of the event, we use the National Centers for Environmental Prediction (NCEP) Final Operational Global Analysis (NCEP-FNL; NCEP/NWS/NOAA/U.S. Department of Commerce 2000) for regional upper-air and surface analyses, visible satellite imagery from the MTSAT-2 

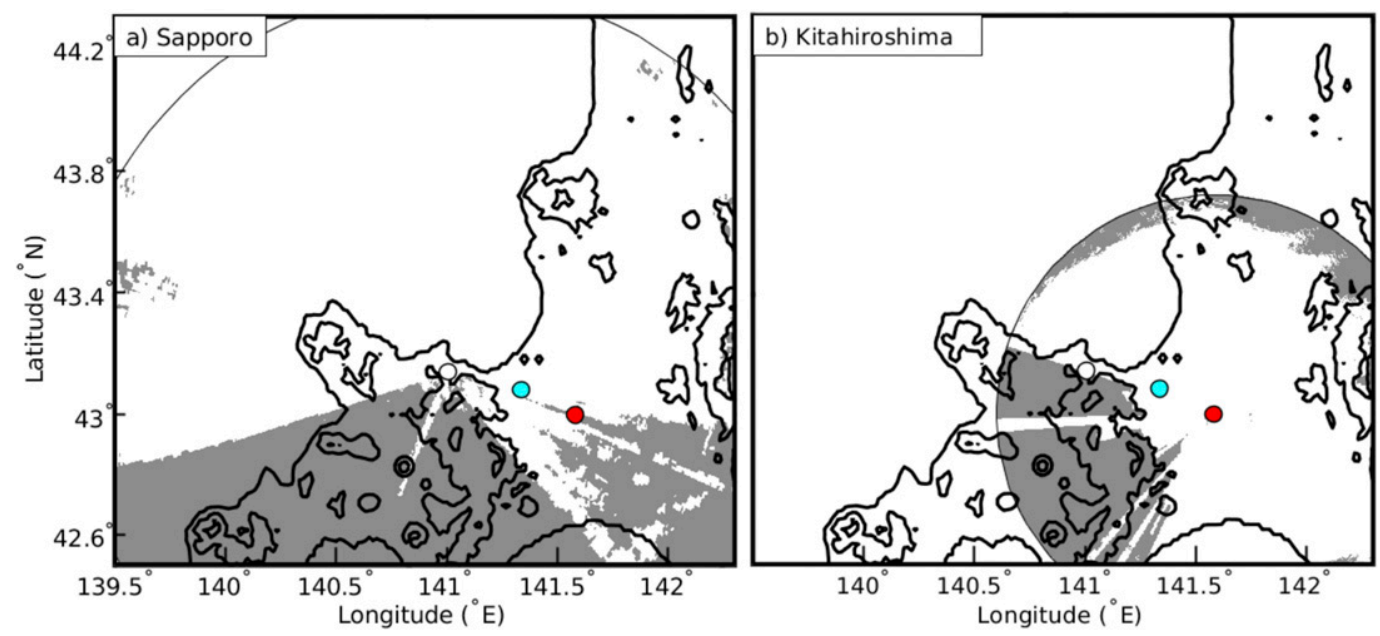

FIG. 3. Beam blockage diagrams for (a) Sapporo radar and (b) Kitahiroshima radar, where gray shading represents beam-blocked areas. White dot represents location of Sapporo radar, red dot represents location of Kitahiroshima radar, and cyan dot is the location of the ILTS meteorological station in Sapporo. Terrain contoured every $400 \mathrm{~m}$ starting at $150 \mathrm{~m}$.

satellite obtained from Kochi University's archives, and twice-daily (0000 and 1200 UTC) upper-air sounding data from the Japan Meteorological Agency (JMA) operational sounding site at Sapporo. Surface observations include liquid precipitation equivalent collected at a number of sites in the JMA Automated Meteorological Data Acquisition System (AMeDAS) network of surface meteorological sites, as well as higher-frequency observations of liquid precipitation equivalent collected at 1-min intervals at the Institute for Low Temperature Science (ILTS) at Hokkaido University, Sapporo (see cyan dot in Fig. 1b for location). We also present hydrometeor size and fall speed observations from a twodimensional video disdrometer (2DVD) at ILTS. The 2DVD was used to determine hydrometeor type following equivalent-diameter-to-fall speed relations presented in Locatelli and Hobbs (1974).

Two radars provide operational coverage of the Ishikari plain and surrounding terrain. A JMA C-band radar (5.6-cm wavelength; located at $\left.43.1389^{\circ} \mathrm{N}, 141.0097^{\circ} \mathrm{E}\right)$ is located on the summit of a small mountain $(749 \mathrm{~m}$ MSL) above the coastal town of Otaru (white dot in Fig. 1b) and surveys Ishikari Bay and the northwestern Ishikari plain, but is blocked to the southeast by the mountains south of the Ishikari plain (Fig. 3a; hereafter referred to as the Sapporo radar, following JMA convention). Sapporo radar volume scans were georeferenced to latitude and longitude coordinates, factoring in a 4/3 Earth radius assumption and standard atmospheric refraction conditions (Rinehart 1997), and were interpolated to a Cartesian grid with $1.5-\mathrm{km}$ horizontal and $0.2-\mathrm{km}$ vertical grid spacing for cross sections.
A dual-polarization X-band (3.1-cm wavelength) radar overseen by the Ministry of Land, Infrastructure, Transport and Tourism (MLIT) is located in the Ishikari plain, southeast of Sapporo in the town of Kitahiroshima, at an elevation of $25 \mathrm{~m}$ MSL (located at $42.9961^{\circ} \mathrm{N}$, $141.5844^{\circ} \mathrm{E}$; red dot in Fig. 1b); it provides coverage over the Ishikari plain and southern Ishikari Bay but is blocked by the surrounding mountains (Fig. 3b; hereafter referred to as the Kitahiroshima radar). Kitahiroshima radar $1.1^{\circ}$ elevation scans were interpolated to a Cartesian grid with 310-m horizontal grid spacing. Plan view radar reflectivity and radarderived precipitation-estimate composites were created by using the highest reflectivity value of the two radars at each overlapping grid point. Radarderived precipitation estimates, tuned using surface precipitation observations from the AMeDAS network, were provided by the JMA and the MLIT for the Sapporo and Kitahiroshima radars, respectively. The Sapporo radar was available for the entire period of study, but the Kitahiroshima radar was only available before 0600 UTC 12 January. Therefore, for times before 0600 UTC, we present composite Sapporo/ Kitahiroshima reflectivity and radar-derived precipitation accumulations, but after 0600 UTC, our analysis is constrained to data from the Sapporo radar.

\section{b. Numerical model simulations}

We used the WRF Model version 3.8.1 with the Advanced Research core (Skamarock and Klemp 2008) to simulate the event. All simulations use three one-way nested domains with $12-$, 4-, and $1.33-\mathrm{km}$ grid spacing 


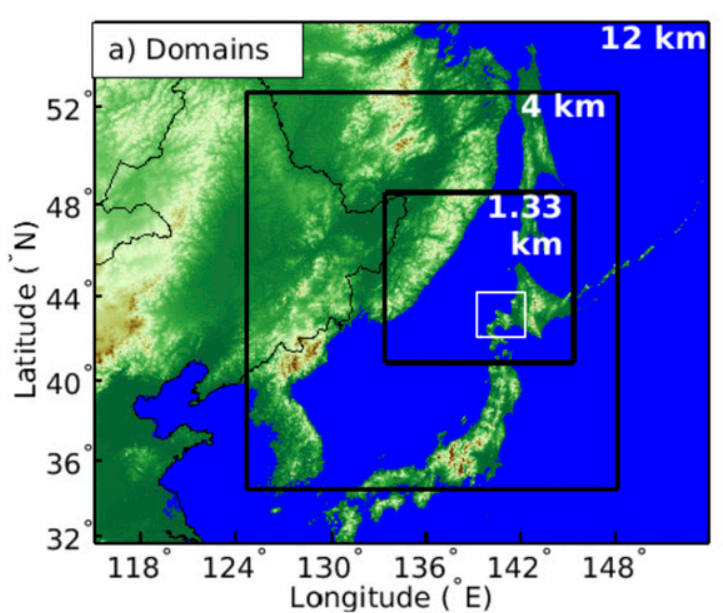

FIG. 4. (a) WRF simulation domains and (b) Control and (c) NoTerrain simulated topography in southwestern Hokkaido. Terrain color filled following scale at bottom right and contoured every $500 \mathrm{~m}$. Black boxes in (a) represent boundaries of WRF domains, and white box in (a) represents location of (b), (c). Yellow and cyan dots in (b) represent locations of simulated soundings used in the study, and the white boxes denote the perimeter of $10 \times 10$ grid points around the dots.
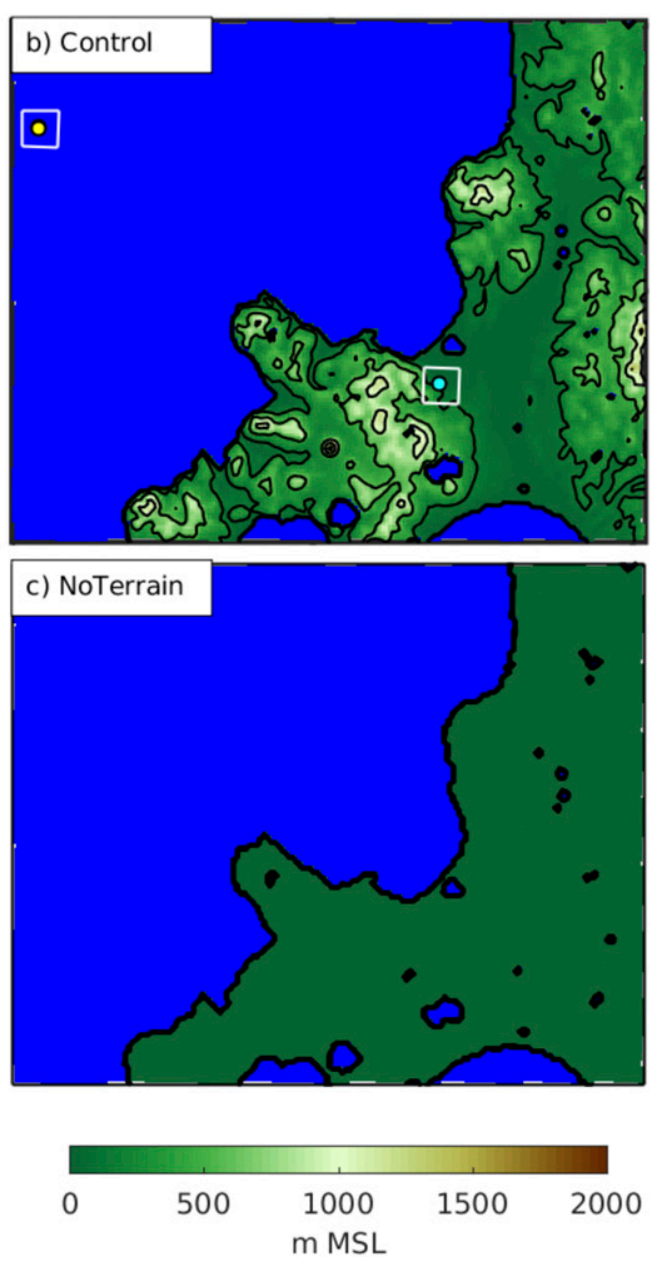

radiation scheme (Dudhia 1989). We use the KainFritsch 2 cumulus parameterization (Kain 2004) in the 12-km domain only.

All simulations were cold-start initialized at 0600 UTC 11 January and run until 1200 UTC 12 January using the NCEP-FNL at $1^{\circ} \times 1^{\circ}$ grid spacing for initial and lateral boundary conditions, land surface conditions, and snow-coverage distribution at 6-h intervals. We use the Moderate Resolution Imaging Spectroradiometer (MODIS) International Geosphere-Biosphere Program (IGBP) 21-category dataset for land-use characteristics. Sea surface temperatures were modified to match the daily NCEP/Marine Modeling and Analysis Branch (MMAB) global sea surface temperature analysis for 11 and 12 January, which assimilates buoy and ship data and satellite-retrieved sea surface temperatures at half-degree resolution. We modified the MMAB sea ice coverage manually based on inspection of MODIS imagery in cloud-free areas during the days preceding and following the event. The Sea of Japan was ice free tion scheme (Iacono et al. 2008), and Dudhia shortwave 
around Hokkaido Island, but we added sea ice around Sakhalin Island, north of Hokkaido, and along the northern Russian shoreline.

We present a simulation (NoTerrain) that is identical to the Control simulation, except that the terrain over all of Hokkaido Island is reduced to the elevation of the Ishikari plain ( $4 \mathrm{~m} \mathrm{MSL}$ ) in all three domains (cf. Figs. $4 \mathrm{~b}, \mathrm{c}$ ). Land use, snow cover, vegetation, and other land surface characteristics in the modified terrain area were not changed. The WRF preprocessing system did, however, adjust the soil temperature, soil moisture, and skin temperature based on elevation and, at the initial time step, replaced the atmosphere where the terrain used to be with lowest-level winds from the NCEP-FNL and a moist adiabatic temperature profile. Given the long $(>18 \mathrm{~h})$ integration time before the onset of our period of interest, as well as the similar large-scale conditions between the Control and NoTerrain runs, we conclude that the differences between the two runs are attributable to changes in orography. The Read-Interpolate-Plot (RIP) visualization program (Stoelinga 2009) was used to calculate air parcel trajectories for the Control and NoTerrain simulations.

\section{Event overview}

A broad upper-level trough centered over eastern Russia and the Sea of Okhotsk produced low-level westerly-to-northwesterly geostrophic flow over the northern Sea of Japan for several days leading up to 12 January (not shown). Between 1200 UTC 11 January and 0000 UTC 12 January, an upper-level short-wave trough progressed southeastward from interior Asia to the Pacific coast (not shown), leading to the development of a surface trough over the Sea of Japan, with low-level $(850 \mathrm{hPa})$ cold-air advection in its wake (Figs. 5a,b). Soundings from Sapporo illustrate a deepening of the boundary layer and a strengthening of the boundary layer directional shear during this period (cf. Figs. 6a,b). By 0300 UTC, a synoptic-scale cloud deck associated with the upper-level trough was exiting the region, and longitudinal- and transverse-mode bands covered much of the Sea of Japan, the latter dominant upstream of Hokkaido (Fig. 5c).

Radar imagery shows a broad shield of precipitation associated with the synoptic-scale cloud deck at 0000 UTC 12 January (cf. Figs. 5c, 7a). This precipitation shield progressed eastward, reaching the Ishikari plain at $\sim 0200$ UTC (Fig. 7b) before exiting the region. Transverse-mode bands developed over the eastern Sea of Japan behind the synoptic-scale precipitation shield, eventually moving over the Ishikari plain and surrounding topography, where they predominated
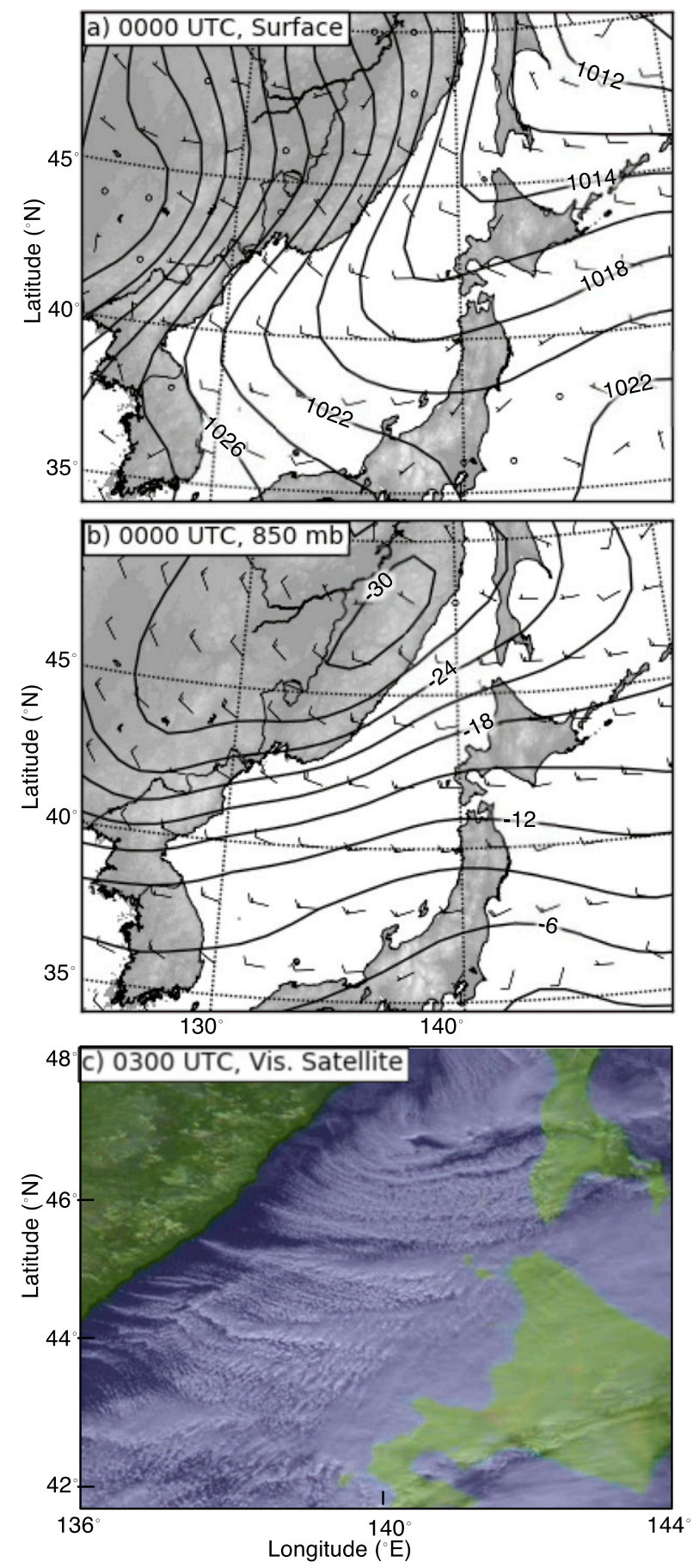

FIG. 5. (a) The 0000 UTC 12 Jan NCEP-FNL mean sea level pressure ( $\mathrm{hPa}$; contoured every $2 \mathrm{hPa}$ ) and wind barbs (full and half barbs denote 5 and $2.5 \mathrm{~m} \mathrm{~s}^{-1}$, respectively); (b) 0000 UTC 12 Jan NCEP-FNL 850-hPa temperatures $\left({ }^{\circ} \mathrm{C}\right.$; contoured every $3^{\circ} \mathrm{C}$ ) and wind barbs (full and half barbs denote 5 and $2.5 \mathrm{~m} \mathrm{~s}^{-1}$, respectively); and (c) 0300 UTC 12 Jan visible satellite imagery. Mean sea level pressure and 850-hPa temperatures smoothed using a seven-point spectral cowbell filter (Barnes et al. 1996). 


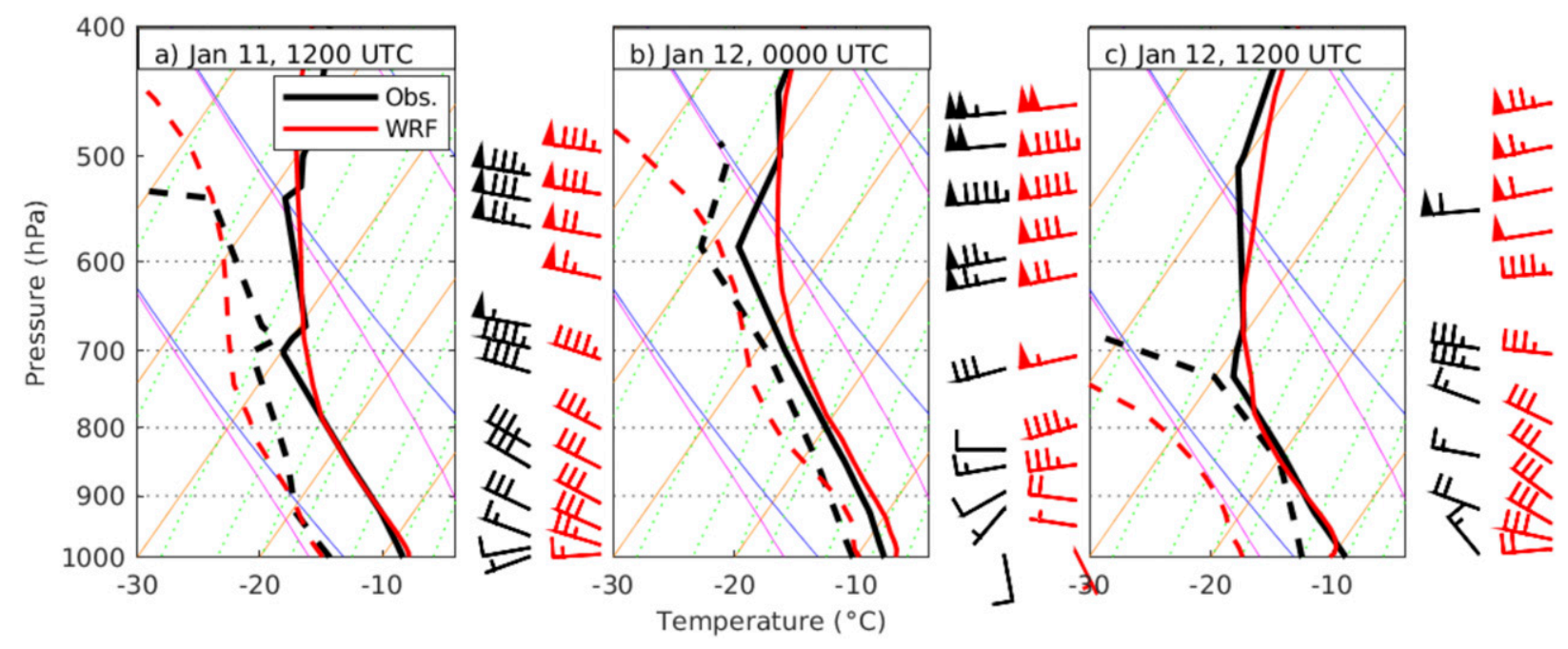

FIG. 6. Observed (black) and Control (red) skew $T$-log $p$ diagrams [temperature $\left({ }^{\circ} \mathrm{C}\right.$; solid line), dewpoint $\left({ }^{\circ} \mathrm{C}\right.$; dashed line), and wind barbs (full and half barbs denote 5 and $2.5 \mathrm{~m} \mathrm{~s}^{-1}$, respectively)] from Sapporo at (a) 1200 UTC 11 Jan, (b) 0000 UTC 12 Jan, and (c) 1200 UTC 12 Jan.

from $\sim 0320$ to 0920 UTC (Figs. 7b-d). These transversemode bands, $\sim 100 \mathrm{~km}$ long and $\sim 10 \mathrm{~km}$ wide as they approached Hokkaido's coastline at regularly spaced intervals, formed midway across the Sea of Japan and were oriented roughly normal to the northwesterly lowlevel boundary layer flow (e.g., Figs. 2, 5c, 7).

Between 0320 and 0600 UTC, transverse-mode bands moving through the Ishikari Bay region intensified preferentially along an elongated enhancement region that began near the tip of the Shakotan Peninsula, extended along the southern side of Ishikari Bay, and penetrated into the southwestern Ishikari plain (e.g., Fig. 7c). A slight backing of band orientation after $\sim 0620$ UTC shifted the zone of enhancement so that it was oriented west-east across Ishikari Bay and extended into the northern Ishikari plain (cf. Figs. 7c,d). By 0920 UTC, the final set of transverse-mode bands had progressed across the region, and convection became disorganized (not shown), consistent with a lowering of the capping inversion and decline in directional boundary layer wind shear shown in the 1200 UTC 12 January Sapporo sounding (Fig. 6c).

Sapporo radar reflectivity frequencies $>10 \mathrm{~dB} Z$ from 0320 to 0600 UTC (Fig. 8) show two distinctive, quasistationary regions of enhanced radar reflectivities. First, an elongated region of high $(>80 \%)$ radar echo frequencies extended off Mt. Yobetsu, through Ishikari Bay, and into the Ishikari plain. Consistent with the radar reflectivity analyses from representative times presented above, this feature closely paralleled the coast of the Shakotan Peninsula from 0320 to 0600 UTC (Fig. 8) but shifted to a more zonal orientation from 0620 to 0920 UTC (not shown), as suggested by Figs. 7c and $7 \mathrm{~d}$. We hereafter refer to this region of echo enhancement as the "elongated enhancement region" for clarity. Second, a similar banded region of precipitation formed over and extended downstream from the Mashike Mountains, north of Ishikari Bay. For brevity, we focus the subsequent analysis on the mechanisms that produced the elongated enhancement region and constrain it to the 0320-0600 UTC period, when the bands' trajectory passed over Sapporo and the southern Ishikari plain.

\section{Radar reflectivity structures}

Higher-frequency $(10 \mathrm{~min})$ radar imagery from 0310 to 0340 UTC illustrates how the transversemode bands intensified and broadened as they entered Ishikari Bay and progressed through the elongated enhancement region (e.g., band Y; Fig. 9), while its vertical structure is revealed using radially oriented cross sections of $0320-0600$ UTC $10-\mathrm{dBZ}$ echo frequencies (Fig. 10; see inset in Fig 10a for crosssectional locations and Fig. 8 for plan view of radar reflectivity frequencies). Cross section A extends northwest from the radar along the Shakotan Peninsula and over Mt. Yobetsu and slices through the northern end of the elongated enhancement region (cf. Figs. 8, 10a). Cross section B extends northeast across Ishikari Bay and the Mashike Mountains. It slices perpendicularly across the elongated enhancement region, which features a core of radar reflectivity frequencies $>80 \%$ that extends to $\sim 1.5 \mathrm{~km}$ MSL and is $\sim 35 \mathrm{~km}$ wide (cf. Figs. $8,10 \mathrm{~b}$ ). A secondary region of high radar echo frequencies, 

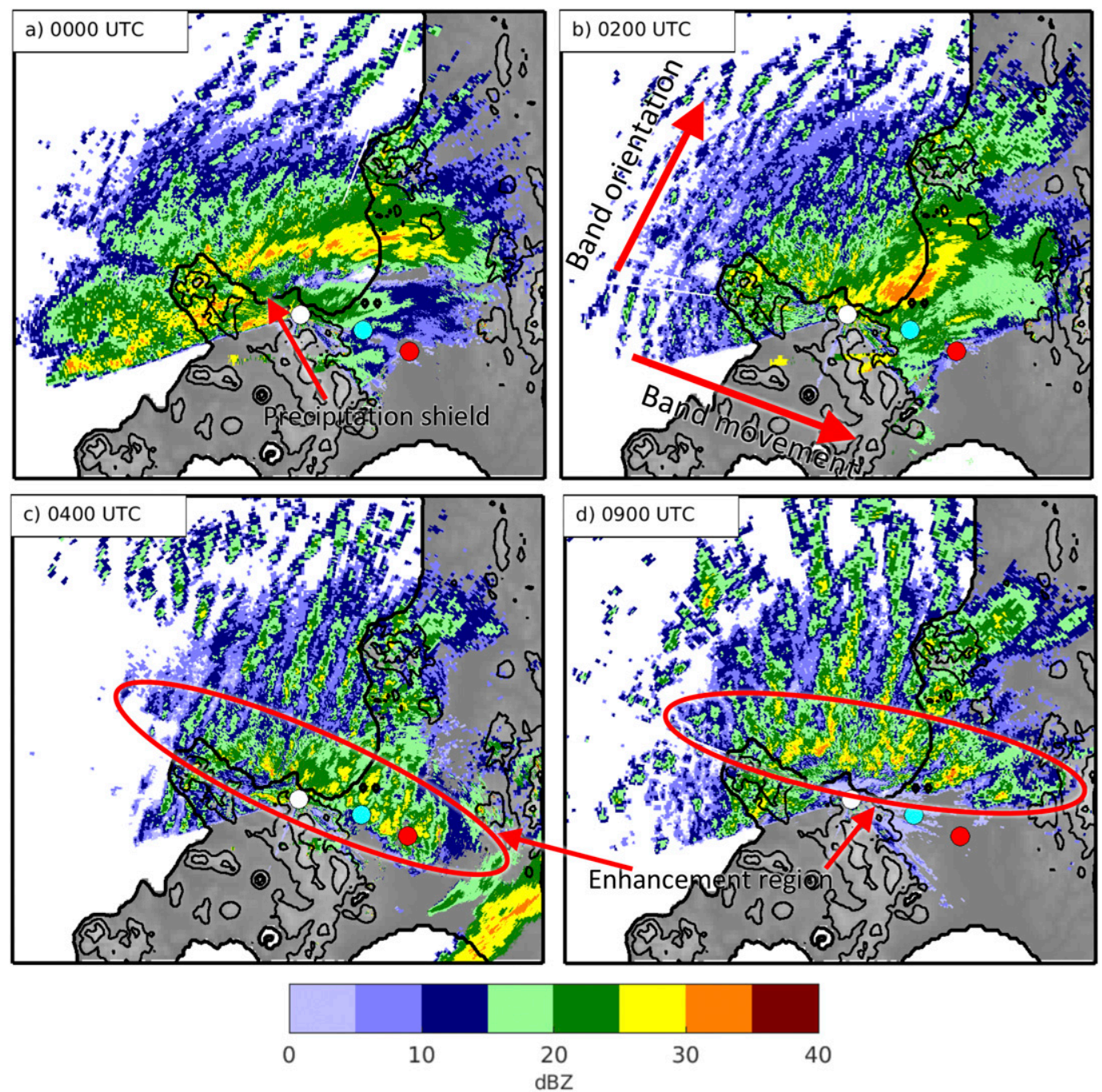

FIG. 7. Composite radar reflectivity (dBZ; color fill as in scale at bottom) at (a) 0000, (b) 0200, and (c) 0400 UTC $12 \mathrm{Jan}$ and (d) Sapporo radar reflectivity (dBZ; color fill as in scale at bottom) at $090012 \mathrm{Jan}$. Terrain contoured every $400 \mathrm{~m}$ starting at $150 \mathrm{~m}$ and color filled with gray. Dots represent the locations of the Sapporo radar (white), ILTS meteorological station (cyan), and Kitahiroshima radar (red).

associated with the enhancement zone extending off the Mashike Mountains, is also visible in this figure.

The above analysis illustrates that transverse-mode bands intensified and broadened as they progressed through Ishikari Bay and into the Ishikari plain, forming the elongated enhancement region. To better understand the mechanisms producing the elongated enhancement region, we now utilize numerical simulations of the event.

\section{Model validation}

Comparison of the Control simulation to the observed event focuses on environmental conditions (i.e., soundings), precipitation characteristics, and precipitation accumulations. Control boundary layer temperature profiles at Sapporo are within $1-1.5^{\circ} \mathrm{C}$ of the available observed profiles prior to (0000 UTC 12 January) and following (1200 UTC 12 January) the study period, but the simulated boundary layer is not as deep and the capping inversion is less defined, especially at 0000 UTC (Figs. 6b,c; black lines are observed and red lines are simulated), ${ }^{1}$ which is a common issue with WRF simulations of events featuring sharp capping inversions (e.g., Coniglio et al. 2013). The Control

\footnotetext{
${ }^{1}$ Simulated soundings are averaged over a $10 \times 10$ gridpoint square around the observed sounding site. For location of the sounding site and averaging box, see cyan dot in Fig. $4 \mathrm{~b}$.
} 


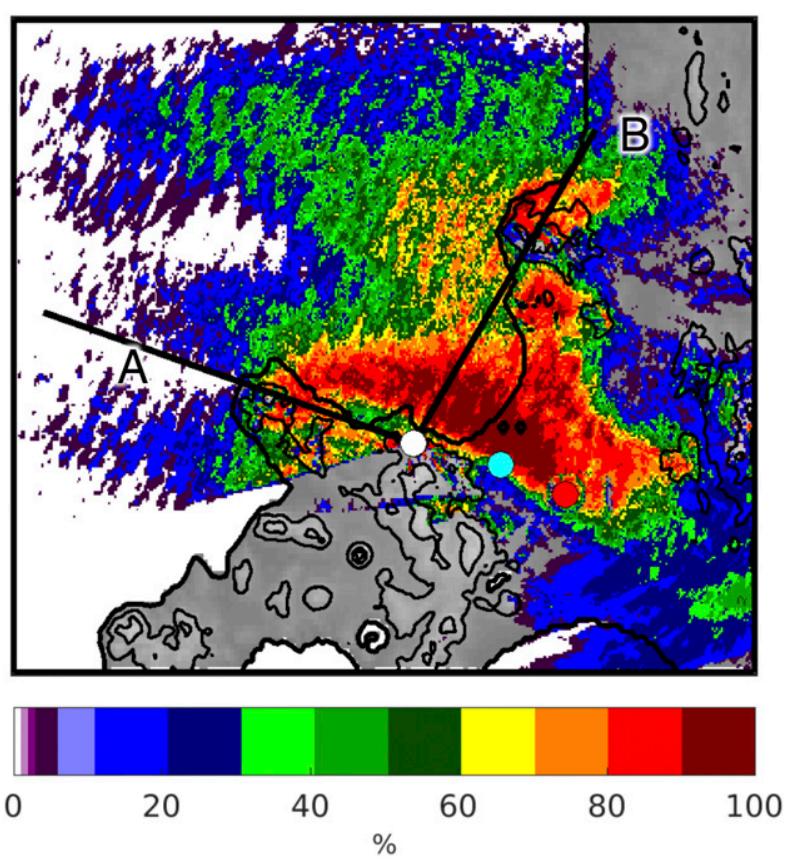

FIG. 8. Composite radar echo frequency $>10 \mathrm{~dB} Z$ (\%; shaded following color scale at bottom) for 0320-0600 UTC $12 \mathrm{Jan}$, with locations of radar cross sections $\mathrm{A}$ and $\mathrm{B}$ superimposed as black lines. Dots represent the locations of the Sapporo radar (white), ILTS meteorological station (cyan), and Kitahiroshima radar (red). Terrain color fill and contours as in Fig. 7.

boundary layer is also drier than observed at 1200 UTC 12 January, likely because the observed sounding passed through a snowband, whereas the Control sounding passed through a clear region between snowbands. A Control atmospheric profile taken through a nearby band produces a nearly identical temperature and moisture profile as the observed sounding (not shown). Wind speeds and directions are a reasonable match, with the exception of somewhat high simulated wind speeds at 1200 UTC 12 January (Fig. 6c).

Control produces transverse-mode bands in the wake of the synoptic-scale precipitation shield, although they are generally shorter, more isolated, and form closer to the Hokkaido coastline than observed (cf. Figs. 7, 11). This is consistent with the shallower boundary layer in Control compared to observed (Fig. 6), which could result in less directional wind shear within the boundary layer. Despite this shortcoming, Control produces a very clear elongated enhancement region that affects the bands as they progress through Ishikari Bay and Ishikari plain. There are two distinctions that complicate the comparison of simulated and observed precipitation features for these times and others: 1) the Control reflectivity plots include echoes in regions where the actual radars are beam blocked, so that in Control we are able to see radar reflectivity echoes to the southwest of Ishikari Bay, whereas in observations they appear confined to the Ishikari Bay region, and 2) the timing of the synoptic-scale precipitation shield's passage, and the subsequent formation of transversemode bands in its wake, lags $\sim 1 \mathrm{~h}$ behind observations. Because of this time lag, we present the Control 0420-0700 UTC period as an analog for the 0320-0600 UTC period presented in observations, a change that is also reflected in the different times included in Figs. 7 and 11.

Control cross sections of time-mean (0420-0700 UTC) hydrometeor mixing ratio along the radar cross sections presented earlier show similar patterns to the observed 10-dBZ radar echo frequency (cf. Figs. 10a,b, and 12a,b). Specifically, in cross section A, hydrometeor mixing ratios increase along the southeastern (leeward) side of Mt. Yobetsu, where the echo frequency maximum occurs (cf. Figs. 10a, 12a). In cross section B, the size, shape, and location of the elongated enhancement region are well represented, especially keeping in mind that radar echo frequencies in Fig. 10b are not shown below $\sim 900 \mathrm{~m}$ MSL (cf. Figs. 10b, 12b). These similarities are also reflected in Control precipitation accumulations, which show good agreement with observations and reproduce the elongated enhancement region as well as the precipitation region extending off the Mashike Mountains, although the magnitude of Control accumulations is slightly smaller, and the elongated enhancement region hugs the terrain more closely than observed (cf. Figs. 13a,b). The region of Control accumulated precipitation south of the elongated enhancement region that does not appear in observations is produced by the synoptic-scale precipitation shield, which lingers longer in Control versus observations.

In summary, Control produces transverse-mode bands during the study period in the appropriate locations, but they are less organized and developed than observed. Nevertheless, the time-mean reflectivities and event-total precipitation distribution produce the salient features of the event, particularly the transition in storm characteristics over and downstream of Mt. Yobetsu and the elongated enhancement region. We now focus our analysis on the processes responsible for these storm characteristics using the Control and NoTerrain simulations.

\section{Hydrometeor mass growth along the elongated enhancement region}

Control time-mean (0420-0700 UTC) surface (i.e., lowest half- $\eta$ level) divergence fields show a persistent 

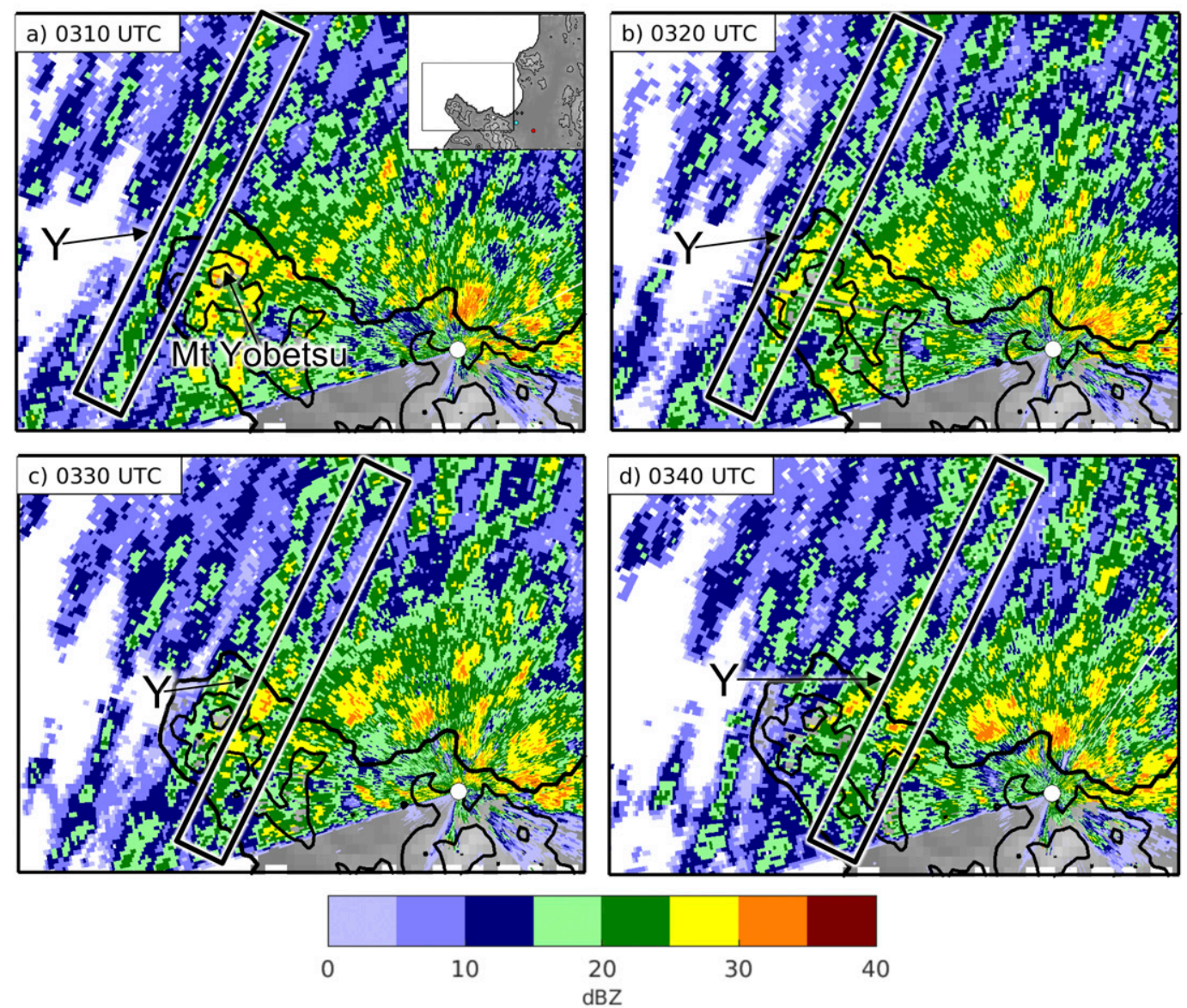

FIG. 9. Sapporo C-band $0.35^{\circ}$-scan radar reflectivity (dBZ; color fill following scale at bottom), at (a) 0310 , (b) 0320, (c) 0330, and (d) 0340 UTC 12 Jan. Terrain color fill and contours as in Fig. 7. For location of area shown, see inset in (a).

region of convergence along the elongated enhancement region (Fig. 14a). Control 900-m MSL ascent fields show two areas of strong ascent along this convergence zone (Fig. 14b): off the northwest slope of Mt. Yobetsu (labeled 1), which is windward with respect to the northwesterly low-level flow, and around Pt. Takashima (labeled 2), particularly offshore and across the Ishikari plain shoreline. A 0440 UTC Control sounding, taken $\sim 100 \mathrm{~km}$ northwest of the Shakotan Peninsula and averaged over a square of $10 \times 10$ grid points (for location

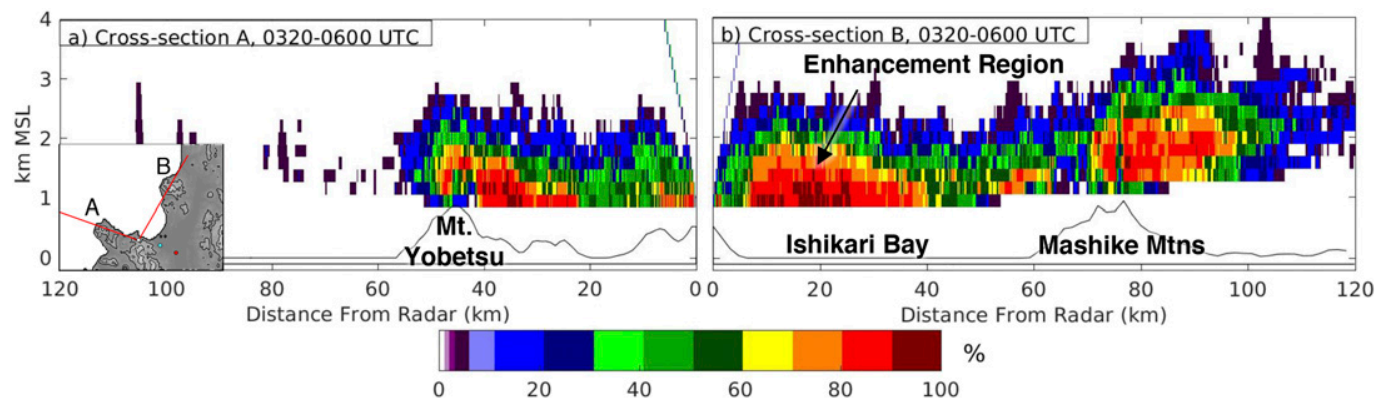

FIG. 10. Frequency of Sapporo radar echoes $>10 \mathrm{dBZ}$ (\%; color fill following color bar at bottom) along (a) cross section A and (b) cross section B for 0320-0600 UTC 12 Jan. For locations of cross sections, see inset in (a). 

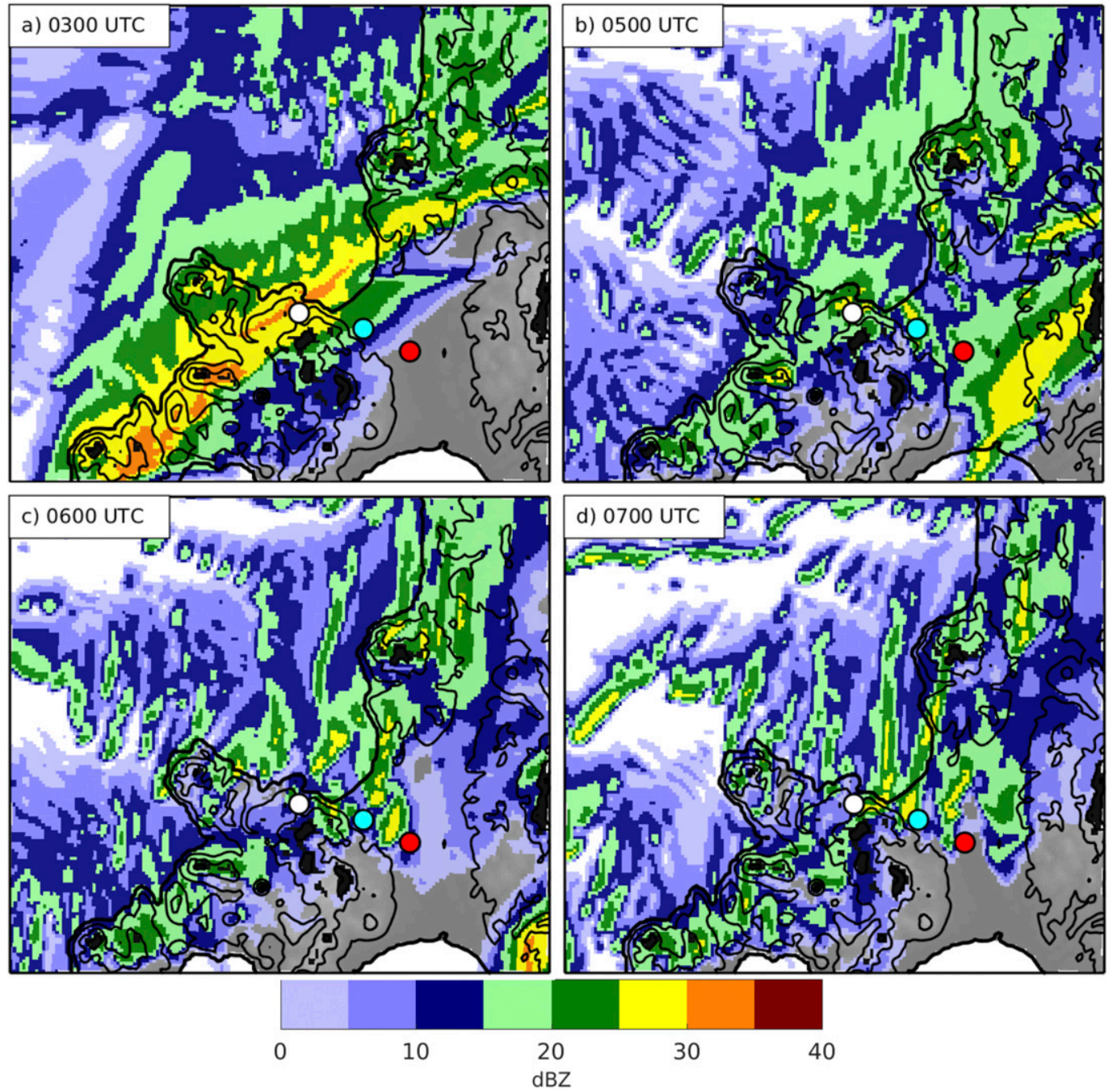

FIG. 11. Control 875-m MSL reflectivity (dBZ; color fill as in scale at bottom) at (a) 0300, (b) 0500, (c) 0600, and (d) 0700 UTC 12 Jan. Terrain color fill and contours as in Fig. 7. Black shading represents terrain that rises above $875 \mathrm{~m}$ MSL. Dots represent the locations of the Sapporo C-band radar (white), ILTS meteorological station (cyan), and Kitahiroshima X-band radar (red).

of sounding, see yellow dot in Fig. 4b), shows a vertical profile of the simulated winds, boundary layer depth, and stability upstream of western Hokkaido (Fig. 15). Directional shear predominated throughout the study period, with northwesterly low-level (i.e., $<\sim 1300 \mathrm{~m}$ MSL) time-mean winds (Figs. 14a, 15) and southwesterly time-mean winds near the top of the boundary layer ( $>\sim 1300$ m MSL; Figs. 14b, 15).

The primary mass growth and loss terms in Control, which uses the Thompson microphysics scheme, are positive rates of "vapor deposition onto snow" (hereafter deposition), negative rates of "vapor deposition onto snow" (hereafter sublimation), and "snow collecting cloud liquid water" (hereafter accretion). Deposition and accretion rates both maximize at a height of $\sim 1200 \mathrm{~m}$ MSL (not shown) within ascent regions 1 and 2 (cf. Figs. 14b, 16a,b), increasing hydrometeor mass along the elongated enhancement region, while subcloud sublimation reduced hydrometeor mass over Ishikari Bay and the lowlands, as well as to the lee (southeast) of Mt. Yobetsu (Fig. 16c). The location of ascent region 2, along with the collocated deposition and accretion maxima, is consistent with the observed increase in radar echo frequencies, as well as the simulated increase in hydrometeor mixing ratio that occurs within the elongated enhancement region downstream of Pt. Takashima (e.g., Figs. 7, 8, 11). These two ascent regions are, therefore, critical to forming and sustaining the elongated enhancement region. The dominance of depositional growth in Control, which produced an average hydrometeor mass over the Ishikari Bay region that was $99 \%$ 


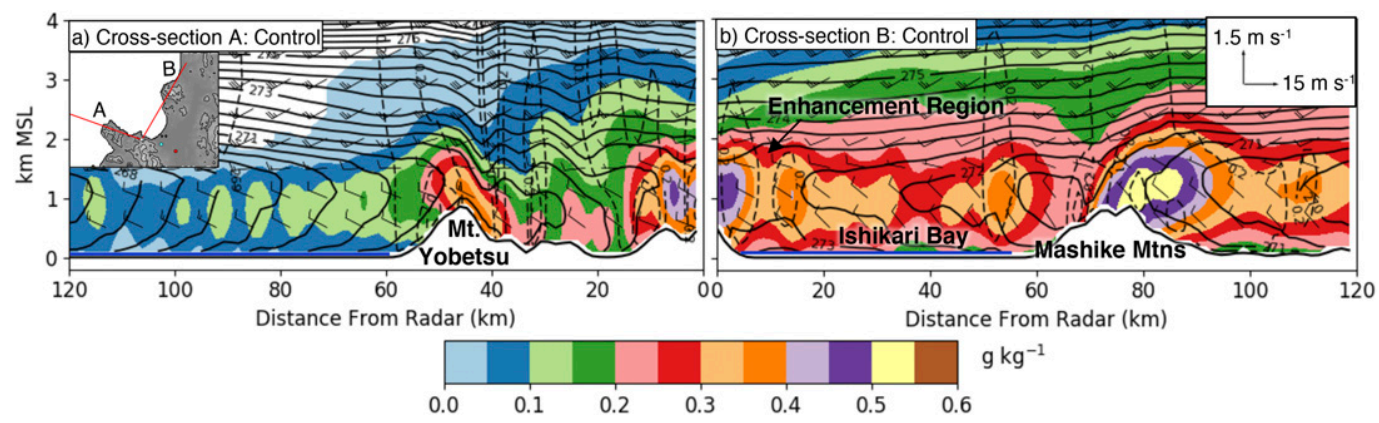

FIG. 12. Control time-mean (0420-0700 UTC 12 Jan) frequency of radar reflectivity values $\geq 20 \mathrm{dBZ}$ ( $\%$; shaded following color bar at bottom), positive vertical velocity (black contours at $0.4 \mathrm{~m} \mathrm{~s}^{-1}$ intervals), equivalent potential temperature ( $\mathrm{K}$; gray contours at $0.5-\mathrm{K}$ intervals), and cross-section-parallel wind vectors (components are vertical velocity and cross-section-parallel horizontal wind) along (a) cross section A and (b) cross section B. Scaled as in inset in upper right of (b). For locations of cross sections, see inset in (a).

snow and $1 \%$ graupel, is similar to ratios seen in lake-effect simulations over the Great Lakes (e.g., Campbell and Steenburgh 2017). It is also consistent with observations, where particles observed at ILTS with the 2DVD were, on average, $92 \%$ aggregate or dendritic forms and $8 \%$ lightly rimed particles or graupel (not shown).

Although ascent is strong within regions 1 and 2, ascent, deposition, and accretion rates are relatively weak along the curving portion of the elongated enhancement region that can be seen in Figs. 8 and 13a, extending off Mt. Yobetsu. Hydrometeor trajectories ending in this section, displayed with time-mean (0420-0700 UTC) 1200-m deposition (black contours) and accumulated precipitation (color fill; Fig. 17a), illustrate how the simulated distribution of hydrometeor mass growth and loss could sustain continued precipitation enhancement along this zone. The hydrometeor trajectories presented here use three-dimensional grid-resolved winds at 10-min intervals, where the vertical component factors in the hydrometeor fall speed at each grid point, output from the Thompson cloud microphysics scheme, in addition to the vertical air velocity. These trajectories begin aloft in the southwesterly flow above $\sim 1500 \mathrm{~m}$ (see Figs. 14 and 15 for wind directions) and pass through the deposition maximum over the northwest slope of Mt. Yobetsu (cf. Figs. 17a,c), curving as they fall into the low-level northwesterly flow. This yields a clockwiseturning pattern of accumulated precipitation at the surface. At the same time, some hydrometeor mass loss due to sublimation occurs near the surface over the water and low-elevation terrain (negative deposition rates in Fig. 17c represent sublimation). Therefore, hydrometeor advection from the primary deposition and accretion maxima windward of Mt. Yobetsu, along clockwise-turning trajectories steered by the boundary layer directional shear, is a likely contributor to the sustained enhancement of precipitation along the elongated enhancement region, in concert with the increased hydrometeor growth produced in ascent regions 1 and 2 .

\section{Mechanisms contributing to convergence along the elongated enhancement region}

We can use the Control and NoTerrain simulations to determine if the elongated enhancement zone is formed by the orography around the Ishikari Bay region or if there are other contributing factors. Comparing the Control and NoTerrain accumulated precipitation reveals that NoTerrain produces less precipitation overall than Control, notably along the elongated enhancement region (cf. Figs. 13b,c and 13d), although it does exhibit some similar precipitation accumulation patterns, such as a precipitation maximum in the Ishikari plain. North of the Ishikari plain, NoTerrain precipitation accumulations do increase just downstream of the shoreline, which is most likely an effect of the change in surface roughness between water and land.

Notably, the convergence zone along the primary axis of the elongated enhancement region is very similar in both runs, although the magnitude of convergence is stronger in Control than in NoTerrain and is shifted slightly south in NoTerrain (cf. Figs. 14a,c). The 900-m vertical velocities along the elongated enhancement region, however, are markedly reduced in NoTerrain (cf. Figs. 14b,d). The strongest ascent maxima in NoTerrain are instead located along the shoreline north of Ishikari plain. This suggests that there is a mechanism other than orography that is producing convergence along the elongated enhancement region.

As low-level northwesterly flow crossed the Sea of Japan, it was warmed by sensible and latent heat fluxes and reached its warmest temperature around 

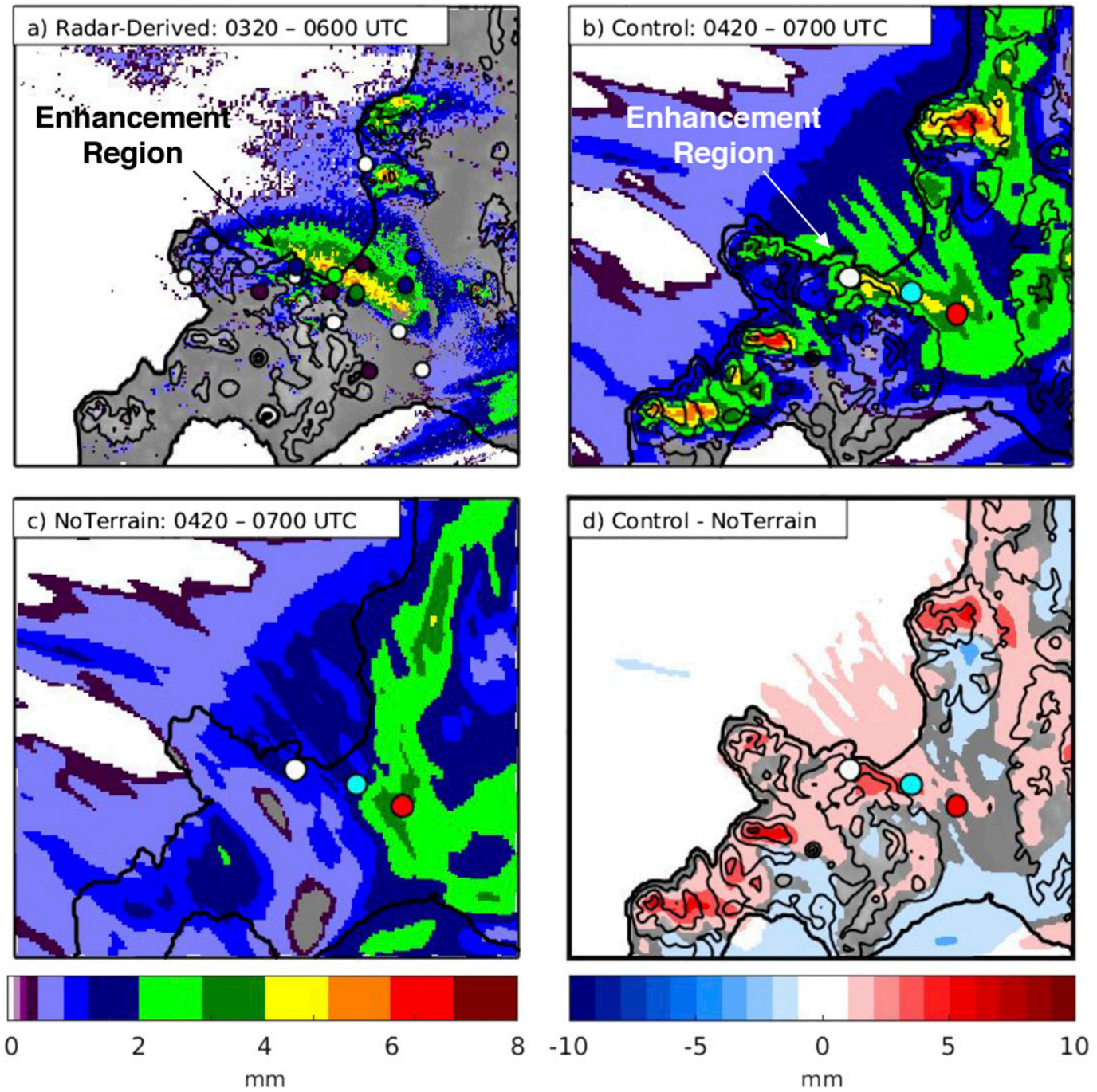

FIG. 13. (a) Radar-derived precipitation accumulation ( $\mathrm{mm}$; shaded following color scale at bottom left) for 0320-0600 UTC. Colored dots represent observed precipitation accumulations at meteorological stations, following color scale at bottom left. Simulated precipitation accumulation $(\mathrm{mm}$; shaded following color scale at bottom left) for 0420-0700 UTC 12 Jan for (b) Control and (c) NoTerrain. (d) Difference between Control and NoTerrain 0420-0700 UTC precipitation ( $\mathrm{mm}$; shaded following color scale at bottom right). Terrain color fill and contours as in Fig. 7. Dots in (b)-(d) represent the locations of the Sapporo C-band radar (white), ILTS meteorological station (cyan), and Kitahiroshima X-band radar (red).

the southeastern shoreline of Ishikari Bay. A tongue of relatively warm Ishikari Bay sea surface temperatures, whose influence is reflected in surface (i.e., lowest half- $\eta$ level) potential temperatures in both Control and NoTerrain (Fig. 18), hugged the northern coastline of the Shakotan Peninsula. These warmer surface temperatures potentially had two effects: 1 ) increasing the instability of the flow along the elongated enhancement region, which could have the dual impact of increasing convection and low-level convergence, and 2) increasing the thermal gradient between Ishikari Bay and the Shakotan Peninsula. The Control cross section B cuts across the elongated enhancement region and illustrates the alignment of the tongue of warmer air (equivalent potential temperature contours), the ascent maximum (vertical velocity contours), and the reflectivity maximum (color fill) over Ishikari Bay at $\sim 0-15 \mathrm{~km}$ from the radar (Fig. 12b; labeled as "Enhancement Region").

An increased thermal gradient between land and water, together with the roughness gradient between these two surfaces, would, in the Northern Hemisphere, produce cyclonic rotation in flow that is parallel to a shoreline with land on the right and water on the left, favoring convergence along the streamwise-right shore 

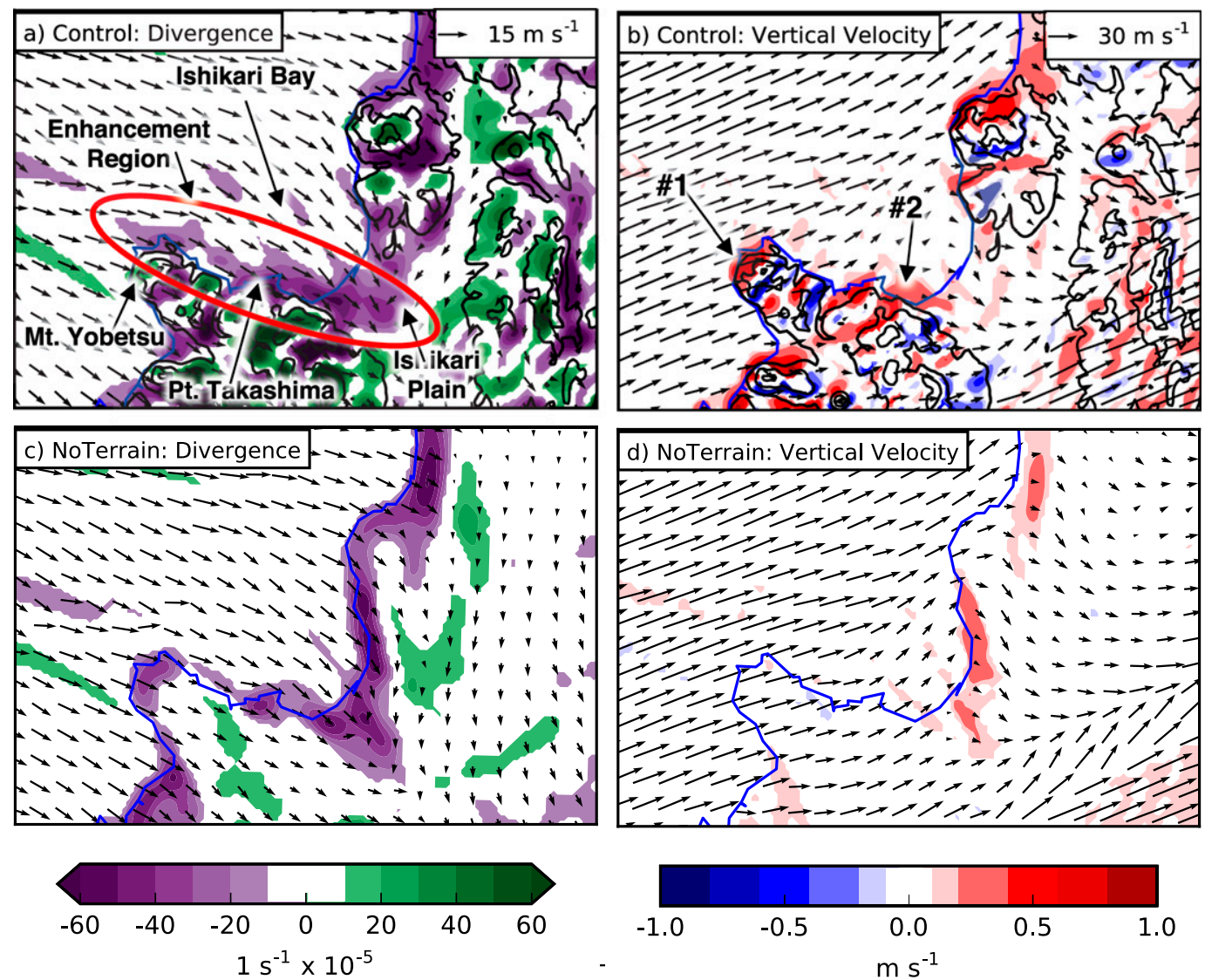

FIG. 14. Control time-mean (0420-0700 UTC 12 Jan) (a) lowest half- $\eta$-level divergence $\left[\mathrm{s}^{-1}, \times 10^{-5}\right.$; shaded following color bar at left. Values less than 0 (purple shading) indicate convergence, and values greater than 0 (green shading) indicate divergence] and lowest half- $\eta$-level wind vectors. (b) Control time-mean (0420-0700 UTC 12 Jan) 900-m MSL vertical velocity ( $\mathrm{m} \mathrm{s}^{-1}$; shaded following color bar at right) and 1800-m MSL wind vectors. (c),(d) As in (a),(b), but for NoTerrain. Note different vector scales between (a),(c) and (b),(d). Divergence and potential temperature smoothed using a seven-point spectral cowbell filter (Barnes et al. 1996). Terrain contoured every $400 \mathrm{~m}$ starting at $150 \mathrm{~m}$.

and divergence along the streamwise-left shore of a lake or bay (e.g., Alestalo and Savijärvi 1985; Markowski and Richardson 2010). This effect has been identified, for example, in numerical simulations of a lake-effect storm over Lake Ontario (Steenburgh and Campbell 2017). In this case, the cyclonic rotation of the flow along the northeastern shoreline of the Shakotan Peninsula, which is the streamwise-right shore of Ishikari Bay, would add to convergence along the elongated enhancement region. This is illustrated with air parcel trajectories ending along three transects cutting across the elongated enhancement region, shown in Fig. 18. Here, blue trajectories represent flow on the south side of the convergence zone, and red trajectories represent flow on the north side. Control trajectories over the Shakotan Peninsula gradually turn toward Ishikari Bay, contributing to convergence along the elongated enhancement region. Although this cyclonic rotation is most distinct in Control, NoTerrain trajectories also rotate toward Ishikari Bay but turn more gradually, so that they converge farther south than in Control (cf. Figs. 18b,c and $18 \mathrm{e}, \mathrm{f})$, producing the slight southward shift of the convergence zone in NoTerrain (cf. Figs. 14a,c). These findings suggest that convergence along the elongated enhancement region is not only produced by the orography of the Shakotan Peninsula, as might be initially assumed, but is also partially a product of the orientation of the shoreline with respect to the prevailing flow and convergence driven by thermal and roughness gradients between land and water.

Control's more extensive region of ascent over Ishikari Bay and Ishikari plain, as compared to NoTerrain (cf. Figs. 14b,d); the stronger and more defined nature of the elongated enhancement region in Control (cf. Figs. 14a,c); and the behavior of air parcel trajectories as they traverse the Shakotan Peninsula (e.g., Fig. 18b), 

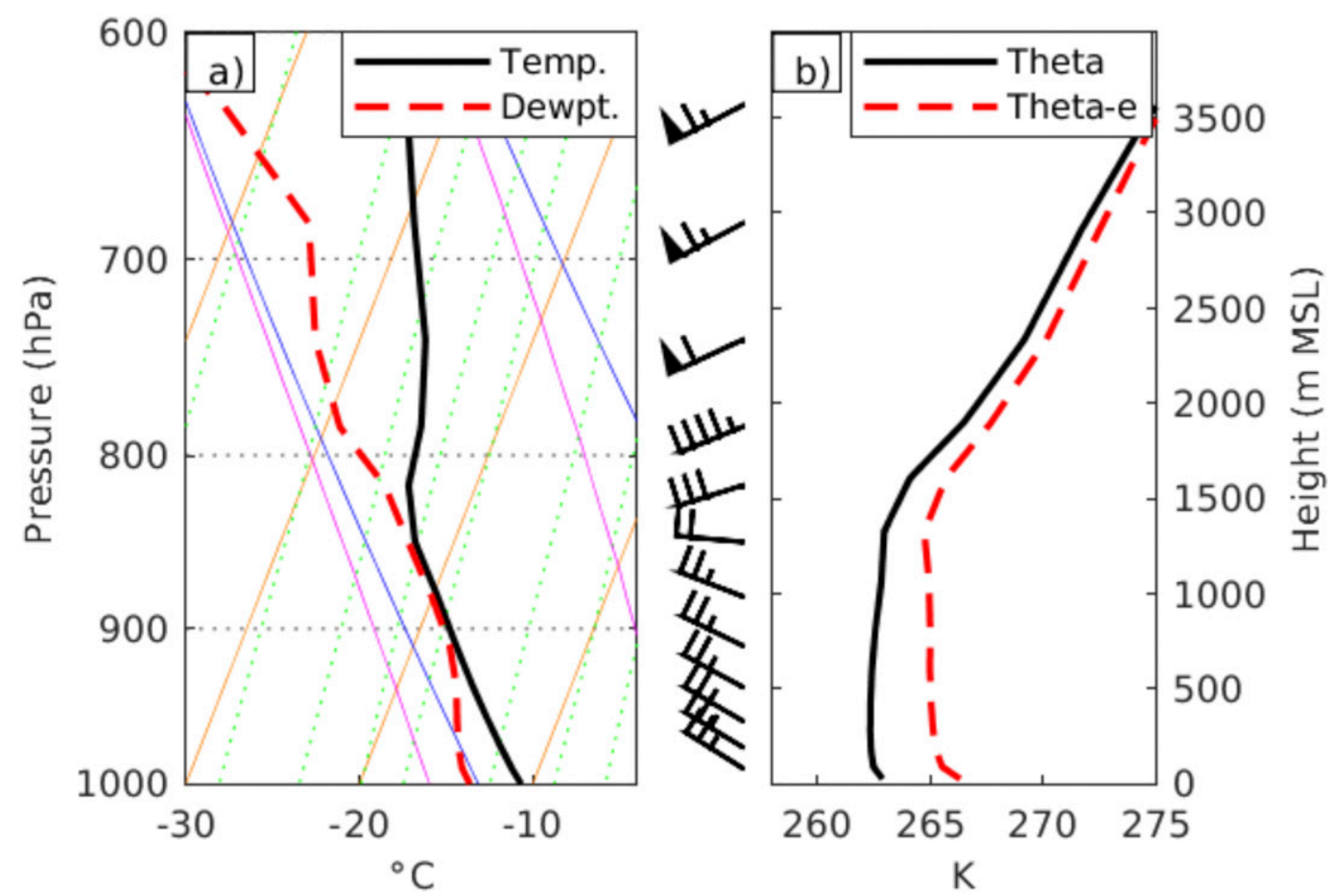

FIG. 15. (a) Control skew $T$-log $p$ diagram [temperature $\left({ }^{\circ} \mathrm{C}\right.$; black solid line), dewpoint $\left({ }^{\circ} \mathrm{C}\right.$; red dashed line), and wind barbs (full and half barbs denote 5 and $2.5 \mathrm{~m} \mathrm{~s}^{-1}$, respectively)] from an atmospheric profile taken $\sim 100 \mathrm{~km}$ northwest of the Shakotan Peninsula and averaged over a $10 \times 10$ square of grid points at 0440 UTC 12 Jan. (b) Potential temperature (K; black line) and equivalent potential temperature (K; red dashed line) from the same profile as in (a).

however, indicate that orography still provides an important contribution to convergence along the elongated enhancement region. The use of indices such as the Froude number or nondimensional mountain height $H$ to diagnose flow blocking is difficult in a situation such as this, with a nonuniform profile of moisture, wind, and stability impinging on a region of complex topography (e.g., Reinecke and Durran 2008). However, we do examine the stability of a simulated atmospheric profile, taken $\sim 100 \mathrm{~km}$ northwest of Mt. Yobetsu at 0440 UTC (Fig. 15). While this profile is potentially unstable below $\sim 300 \mathrm{~m}$ MSL, it has a bulk Brunt-Väisälä frequency of $0.0054 \mathrm{~s}^{-1}$ (calculated following Reinecke and Durran 2008) and an average wind speed of $12.9 \mathrm{~m} \mathrm{~s}^{-1}$ between the surface and $1595 \mathrm{~m}$ (slightly above crest level but within the capping inversion). This yields a nondimensional mountain height of 0.67 when these values are used with a mountain height of $1595 \mathrm{~m}$. Values much smaller than unity generally indicate a tendency toward flow deflection, but this value is near unity, indicating the possibility of both orographically forced flow deflection and ascent. These findings are consistent with the presence of both the ascent maxima found along the northwestfacing aspects of the terrain along the Shakotan Peninsula
(Fig. 14b) and the deflection of flow by the Shakotan Peninsula's orography toward the elongated enhancement region (cf. Figs. 14a,c; cf. Figs. 18a-c and 18d-f).

These results indicate that the elongated enhancement region is produced by both nonorographic and orographic factors. Western Hokkaido's shoreline geometry, in particular the concave shape of Ishikari Bay and the orientation of the Shakotan Peninsula on the streamwise-right side of the low-level flow, adds to convergence along the elongated enhancement region due to thermal and roughness gradients between land and water, and these effects are accentuated by the deflection of flow by the Shakotan Peninsula's orography.

\section{Summary and conclusions}

This study used observations and WRF simulations to examine the radar reflectivity structures and precipitation distribution patterns produced by the interactions of a transverse-mode sea-effect storm with the complex geography of western Hokkaido Island, Japan. Our analysis shows that both orographic and nonorographic effects around Hokkaido's shoreline contributed to the observed precipitation distribution. 

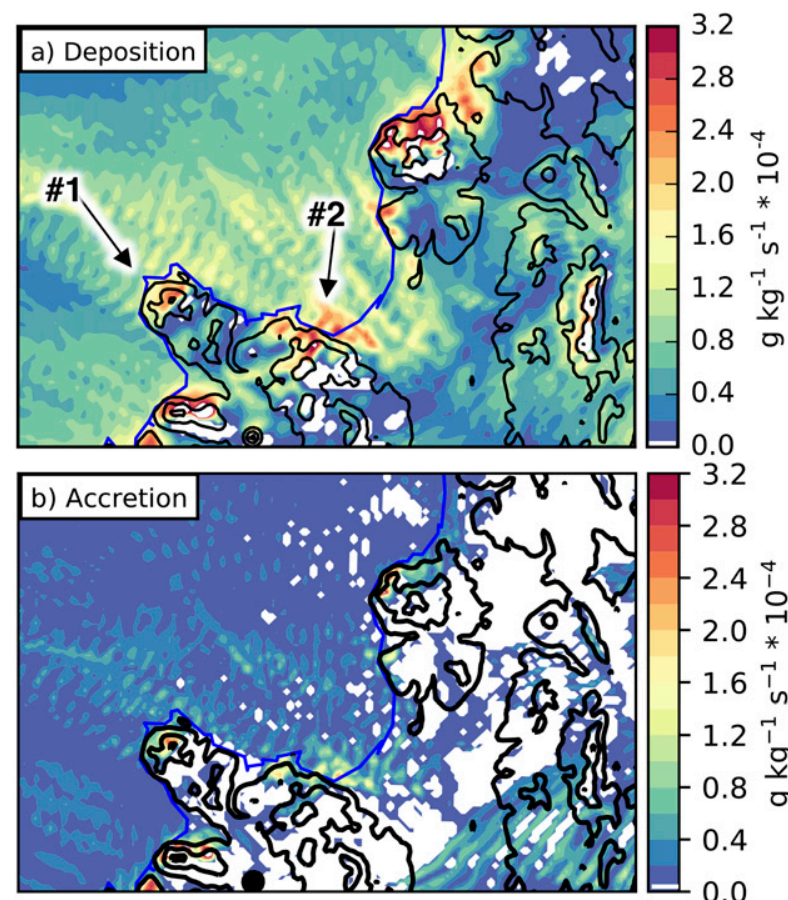

3.2
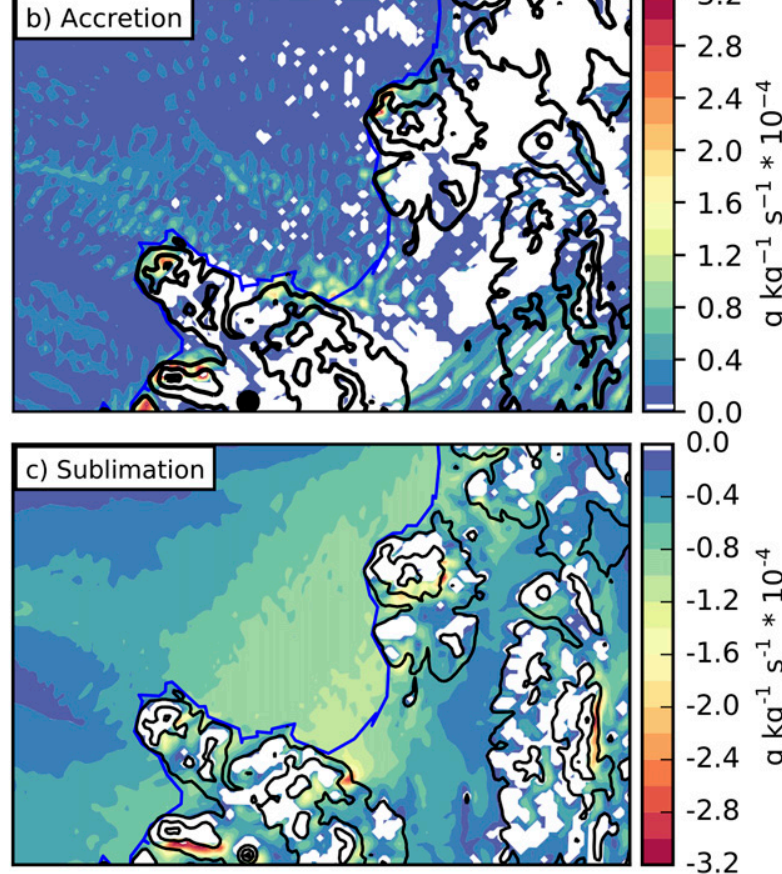

0.0

$-0.4$

$-0.8+$

$-1.2 \stackrel{\circ}{\stackrel{\circ}{ }}$

-1.6 in

-2.0 ํำ

-2.4 का

$-2.8$

$-3.2$

FIG. 16. Time-mean (0420-0700 UTC 12 Jan) hydrometeor mass tendencies: (a) 1200-m deposition, (b) 1200-m accretion, and (c) lowest half- $\eta$-level sublimation $\left(\mathrm{g} \mathrm{kg}^{-1} \mathrm{~s}^{-1}, \times 10^{-4}\right.$; shaded following color bars at right), smoothed using a seven-point spectral cowbell filter (Barnes et al. 1996). White shading denotes values of zero for the relevant tendency. Terrain contoured every $400 \mathrm{~m}$ starting at $150 \mathrm{~m}$, and coastline contoured with blue line.

Regularly spaced transverse-mode bands, oriented roughly perpendicular to the northwesterly low-level boundary layer flow, impacted Hokkaido's Ishikari Bay region between 0320 and 0920 UTC 12 January 2014. The bands were $\sim 100 \mathrm{~km}$ long and $\sim 10 \mathrm{~km}$ wide as they entered Ishikari Bay, and they intensified and broadened along a quasi-stationary, elongated enhancement region that began near Mt. Yobetsu, extended along the southern side of Ishikari Bay, and penetrated into the Ishikari plain.

Simulated hydrometeor mass growth along the elongated enhancement region primarily occurred within
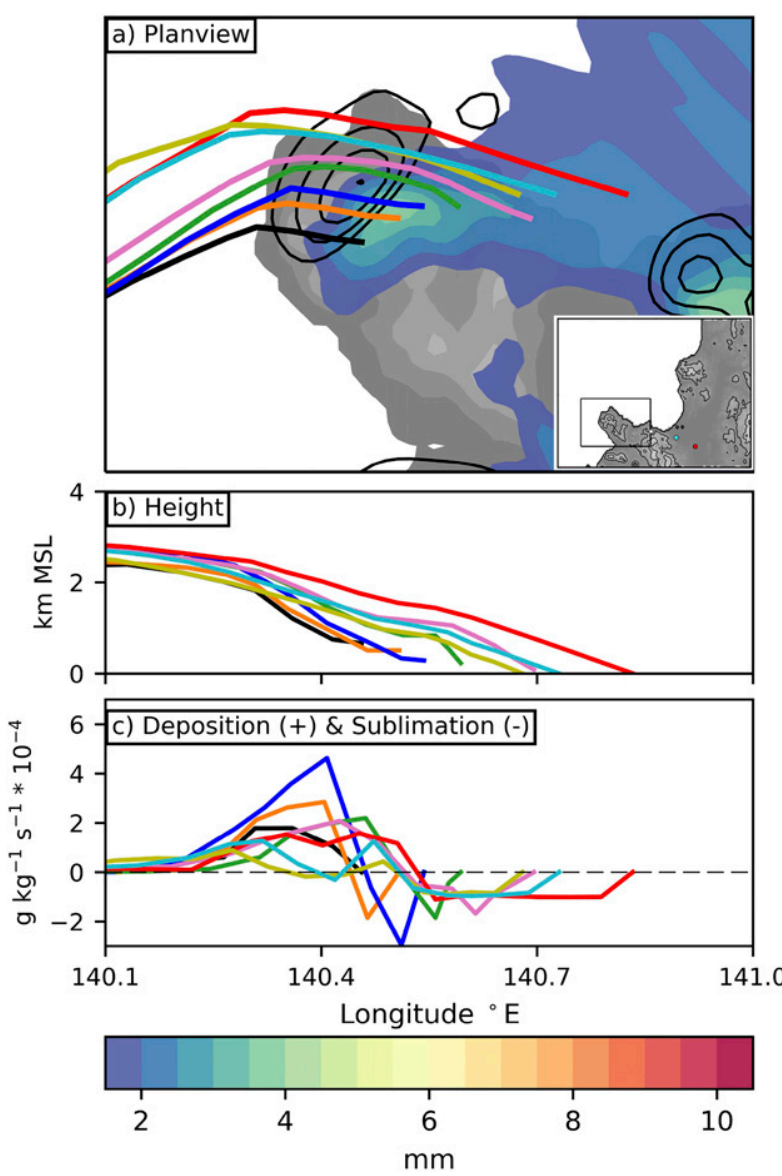

FIG. 17. (a) Control time-mean (0420-0700 UTC 12 Jan) 1200-m deposition rate [contoured every $0.3 \times 10^{-4} \mathrm{~g} \mathrm{~kg}^{-1} \mathrm{~s}^{-1}$ starting at $1.2 \times 10^{-4} \mathrm{~g} \mathrm{~kg}^{-1} \mathrm{~s}^{-1}$ and smoothed using a seven-point spectral cowbell filter (Barnes et al. 1996)] and accumulated precipitation (mm; color fill following color bar at bottom) overlain with hydrometeor trajectories (colored lines) ending along the elongated enhancement region at 0600 UTC 12 Jan. Terrain color filled in gray. For location of area shown, see inset in (a). (b) Height (m MSL) and (c) deposition (positive values) and sublimation (negative values) rate $\left(\mathrm{g} \mathrm{kg}^{-1} \mathrm{~s}^{-1}, \times 10^{-4}\right)$ of hydrometeor trajectories shown in (a).

two major regions of ascent: 1) along the northeast slope of Mt. Yobetsu and 2) near Pt. Takashima along the Ishikari Bay shoreline. Hydrometeor advection through the first ascent region, and along clockwise-turning trajectories steered by the boundary layer directional shear, contributed to sustained precipitation enhancement along a curving portion of the elongated enhancement region downstream of Mt. Yobetsu. Hydrometeor mass growth in the second ascent region intensified echoes as they passed Pt. Takashima and continued into Ishikari Bay and the Ishikari plain. We identify two potential contributors to the convergence zone that sustained hydrometeor mass growth along the elongated enhancement region: 1) low-level orographic 

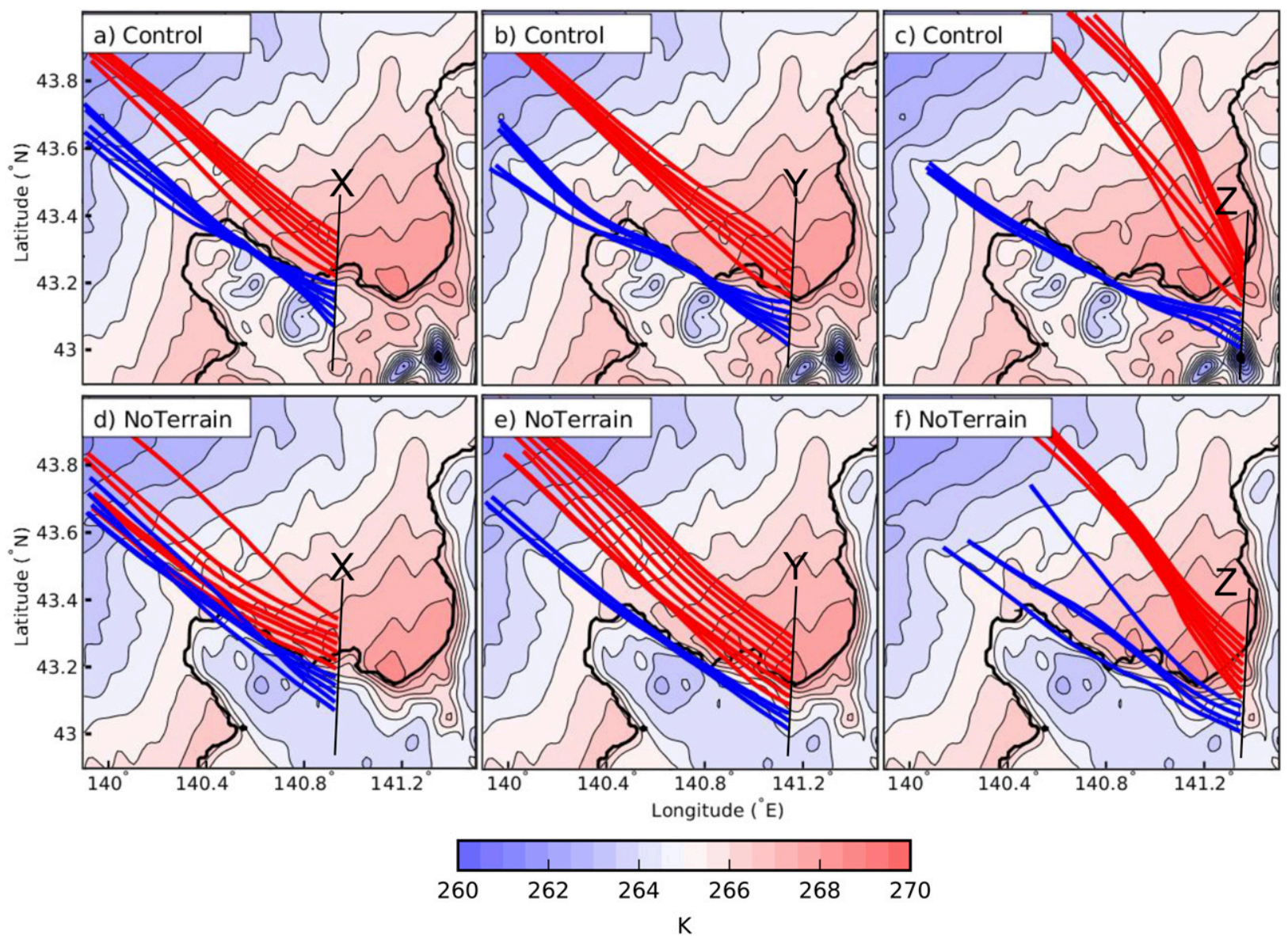

FIG. 18. (a)-(c) Control time-mean (0420-0700 UTC 12 Jan) lowest half- $\eta$-level potential temperature (K; shaded following color bar at bottom and contoured at $0.5-\mathrm{K}$ intervals) overlain with air parcel trajectories ending at the lowest half- $\eta$ level along three lines (labeled $\mathrm{A}, \mathrm{B}$, and C) that extend across the elongated enhancement region at $0700 \mathrm{UTC} 12 \mathrm{Jan}$. Blue trajectories end south of the convergence zone and red trajectories end north of the convergence zone. Coastline outlined with thick black line. (d)-(f) As in (a)-(c), but for NoTerrain run.

flow deflection by the mountainous Shakotan Peninsula and 2) the parallel orientation of the Ishikari Bay shoreline with respect to the low-level flow, which could accentuate the effects of thermal and roughness gradients between land and water, cyclonically rotating the low-level northwesterly flow toward the convergence zone.

Radar reflectivity structures similar to the ones documented here have been noted in earlier studies of Ishikari Bay precipitation mechanisms. For example, Kikuchi et al. (1987) used radar to document the deflection of incoming flow by the Shakotan Peninsula and the resultant intensification and shift in orientation of incoming longitudinal-mode bands as they traversed Ishikari Bay. A similar phenomenon was documented along the coast of the Hokuriku region of Honshu Island, Japan, by Yoshihara et al. (2004). These studies were, however, limited given the constraints of the radar observations, and Kikuchi et al. (1987) attributed the cyclonic rotation of the flow solely to orographic blocking.

The current study, in contrast, indicates that in combination with orographic deflection, thermal effects and the orientation of the incoming flow with respect to the shoreline may have contributed to band enhancement along the elongated enhancement region, although additional sensitivity studies are needed to quantify the impact of these factors. The importance of shoreline geometry in sea- and lake-effect precipitation distributions was recently noted by Steenburgh and Campbell (2017) and Campbell and Steenburgh (2017), who documented the formation of similar airmass boundaries over and around Lake Ontario. Nagata (1991) found that both thermal gradients between the Korean Peninsula and the Sea of Japan, as well as the orography of the Korean Peninsula, similarly contribute to 
the formation of the JPCZ along the Eurasian coast of the Sea of Japan. It is probable that similar thermal gradients form in other sea- and lake-effect regions with complex shoreline geometries and contribute to many of the observed precipitation features and distribution patterns found during these events.

These findings highlight the importance of relatively subtle influences of shoreline topography on the distribution of precipitation produced by sea-effect events and will help improve the forecasting of these events in the future by providing a basic framework with which to consider the potential impacts of orography and shoreline configuration around the downstream shoreline. Future work should include a detailed sensitivity study examining the specific role of thermal and roughness gradients in this event, along with a climatological assessment of orographic and coastline impacts. The impact of orography and shoreline geometry, both in Japan and in other sea- and lake-effect regions, should be examined using idealized modeling frameworks in order to test these hypotheses more thoroughly. Future observational studies could be improved by the deployment of additional high-quality precipitation gauges and meteorological stations in more remote regions of Hokkaido.

Acknowledgments. Comments from Justin Minder, Bart Geerts, John Horel, Ed Zipser, Sarah Bang, Peter Veals, Tyler West, and three anonymous reviewers improved the manuscript. Tom Gowan provided valuable assistance with calculating hydrometeor trajectories. We thank the University of Utah Center for High Performance Computing, the University of Hokkaido, the JMA, and NCEP for the provision of datasets, software, and/or computer time and services. This material is based upon work supported by the Japan Society for the Promotion of Science and the following National Science Foundation grants: AGS-1635654, AGS-1262090, and IIA-1414430. Any opinions, findings, conclusions, or recommendations expressed are those of the authors and do not necessarily reflect the views of the National Science Foundation.

\section{REFERENCES}

Alcott, T. I., and W. J. Steenburgh, 2013: Orographic influences on a Great Salt Lake-effect snowstorm. Mon. Wea. Rev., 141, 2432-2450, https://doi.org/10.1175/MWR-D-12-00328.1.

Alestalo, M., and H. Savijärvi, 1985: Mesoscale circulations in a hydrostatic model: Coastal convergence and orographic lifting. Tellus, 37A, 156-162, https://doi.org/10.1111/j.16000870.1985.tb00277.x.

Asai, T., 1970: Stability of a plane parallel flow with variable vertical shear and unstable stratification. J. Meteor. Soc. Japan, 48, 129-139, https://doi.org/10.2151/jmsj1965.48.2_129.
_ 1972: Thermal instability of a shear flow turning the direction with height. J. Meteor. Soc. Japan, 50, 525-532, https://doi.org/ 10.2151/jmsj1965.50.6_525.

Barnes, S. L., F. Caracena, and A. Marroquin, 1996: Extracting synoptic-scale diagnostic information from mesoscale models: The eta model, gravity waves, and quasigeostrophic diagnostics. Bull. Amer. Meteor. Soc., 77, 519-528, https://doi.org/10.1175/ 1520-0477(1996)077<0519:ESSDIF>2.0.CO;2.

Byrd, G. P., R. A. Anstett, J. E. Heim, and D. M. Usinski, 1991: Mobile sounding observations of lake-effect snowbands in western and central New York. Mon. Wea. Rev., 119, 2323-2332, https://doi.org/10.1175/1520-0493(1991)119<2323:MSOOLE >2.0. $\mathrm{CO} ; 2$.

Campbell, L. S., and W. J. Steenburgh, 2017: The OWLeS IOP2b lake-effect snowstorm: Mechanisms contributing to the Tug Hill precipitation maximum. Mon. Wea. Rev., 145, 2461-2478, https://doi.org/10.1175/MWR-D-16-0461.1.

Chang, S. S., and R. R. Braham, 1991: Observational study of a convective internal boundary layer over Lake Michigan. J. Atmos. Sci., 48, 2265-2279, https://doi.org/10.1175/1520-0469(1991)048<2265: OSOACI $>2.0 . \mathrm{CO} ; 2$.

Chen, F., and J. Dudhia, 2001: Coupling an advanced land surfacehydrology model with the Penn State-NCAR MM5 modeling system. Part II: Preliminary model validation. Mon. Wea. Rev., 129, 587-604, https://doi.org/10.1175/1520-0493(2001)129<0587: CAALSH $>2.0 . \mathrm{CO} ; 2$.

Coniglio, M. C., J. Correia, P. T. Marsh, and F. Kong, 2013: Verification of convection-allowing WRF Model forecasts of the planetary boundary layer using sounding observations. Wea. Forecasting, 28, 842-862, https://doi.org/10.1175/WAF-D-1200103.1.

Conrick, R., H. D. Reeves, and S. Zhong, 2015: The dependence of QPF on the choice of boundary- and surface-layer parameterization for a lake-effect snowstorm. J. Appl. Meteor. Climatol., 54, 1177-1190, https://doi.org/10.1175/JAMC-D-14-0291.1.

Dudhia, J., 1989: Numerical study of convection observed during the Winter Monsoon Experiment using a mesoscale two-dimensional model. J. Atmos. Sci., 46, 3077-3107, https://doi.org/10.1175/ 1520-0469(1989)046<3077:NSOCOD>2.0.CO;2.

Eito, H., T. Kato, M. Yoshizaki, and A. Adachi, 2005: Numerical simulation of the quasi- stationary snowband observed over the southern coastal area of the Sea of Japan on 16 January 2001. J. Meteor. Soc. Japan, 83, 551-576, https://doi.org/ 10.2151/jmsj.83.551.

- M. Murakami, C. Muroi, T. Kato, S. Hayashi, H. Kuroiwa, and M. Yoshizaki, 2010: The structure and formation mechanism of transversal cloud bands associated with the Japan-Sea polar-airmass convergence zone. J. Meteor. Soc. Japan, 88, 625-648, https://doi.org/10.2151/jmsj.2010-402.

Ellis, A. W., and J. J. Johnson, 2004: Hydroclimatic analysis of snowfall trends associated with the North American Great Lakes. J. Hydrometeor., 5, 471-486, https://doi.org/10.1175/ 1525-7541(2004)005<0471:HAOSTA > 2.0.CO;2.

Fujiyoshi, Y., K. Tsuboki, S. Satoh, and G. Wakahama, 1992: Three-dimensional radar echo structure of a snow band formed on the lee side of a mountain. J. Meteor. Soc. Japan, 70, 11-24, https://doi.org/10.2151/jmsj1965.70.1_11.

Harimaya, T., and M. Satol, 1992: The riming proportion in snow particles falling on coastal areas. J. Meteor. Soc. Japan, 70, 57-65, https://doi.org/10.2151/jmsj1965.70.1_57.

_ , and N. Kanemura, 1995: Comparison of the riming growth of snow particles between coastal and inland areas. J. Meteor. Soc. Japan, 73, 25-36, https://doi.org/10.2151/jmsj1965.73.1_25. 
Hong, S.-Y., Y. Noh, and J. Dudhia, 2006: A new vertical diffusion package with an explicit treatment of entrainment processes. Mon. Wea. Rev., 134, 2318-2341, https://doi.org/10.1175/MWR3199.1.

Hozumi, K., and C. Magono, 1984: The cloud structure of convergent cloud bands over the Japan Sea in winter monsoon period. J. Meteor. Soc. Japan, 62, 522-533, https://doi.org/10.2151/jmsj1965.62.3_522.

Iacono, M. J., J. S. Delamere, E. J. Mlawer, M. W. Shephard, S. A. Clough, and W. D. Collins, 2008: Radiative forcing by longlived greenhouse gases: Calculations with the AER radiative transfer models. J. Geophys. Res., 113, D13103, https://doi.org/ 10.1029/2008JD009944.

Jiménez, P. A., J. Dudhia, J. F. González-Rouco, J. Navarro, J. P. Montávez, and E. García- Bustamante, 2012: A revised scheme for the WRF surface layer formulation. Mon. Wea. Rev., 140, 898-918, https://doi.org/10.1175/MWR-D-11-00056.1.

Kain, J. S., 2004: The Kain-Fritsch convective parameterization: An update. J. Appl. Meteor., 43, 170-181, https://doi.org/ 10.1175/1520-0450(2004)043<0170:TKCPAU>2.0.CO;2.

Katsumata, M., H. Uyeda, and K. Kikuchi, 1998: Characteristics of a cloud band off the west coast of Hokkaido Island as determined from AVHRR/NOAA, SSM/I and radar data. J. Meteor. Soc. Japan, 76, 169-189, https://doi.org/10.2151/ jmsj1965.76.2_169.

Kawase, H., M. Hara, T. Yoshikane, N. N. Ishizaki, F. Uno, H. Hatsushika, and F. Kimura, 2013: Altitude dependency of future snow cover changes over central Japan evaluated by a regional climate model. J. Geophys. Res. Atmos., 118, 12444 12 457, https://doi.org/10.1002/2013JD020429.

Kelly, R. D., 1982: A single Doppler radar study of horizontal-roll convection in a lake-effect snow storm. J. Atmos. Sci., 39, 1521-1531, https://doi.org/10.1175/1520-0469(1982)039<1521: ASDRSO $>2.0 . \mathrm{CO} ; 2$.

_- 1984: Horizontal roll and boundary-layer interrelationships observed over Lake Michigan. J. Atmos. Sci., 41, 18161826, https://doi.org/10.1175/1520-0469(1984)041<1816: HRABLI>2.0.CO;2.

Kikuchi, K., S. Azumane, M. Murakami, and T. Taniguchi, 1987: Precipitating snow clouds during winter monsoon seasons influenced by topography of the Shakotan Peninsula, Hokkaido Island, Japan (SHAROP). Environ. Sci. Hokkaido, 10, 109-128.

Kristovich, D. A. R., 1993: Mean circulations of boundary-layer rolls in lake-effect snow storms. Bound.-Layer Meteor., 63 , 293-315, https://doi.org/10.1007/BF00710463.

—_, and Coauthors, 2017: The Ontario Winter Lake-effect Systems (OWLeS) field campaign: Scientific and educational adventures to further our knowledge and prediction of lakeeffect storms. Bull. Amer. Meteor. Soc., 98, 315-332, https:// doi.org/10.1175/BAMS-D-15-00034.1.

Laird, N. F., J. Desrochers, and M. Payer, 2009: Climatology of lake-effect precipitation events over Lake Champlain. J. Appl. Meteor. Climatol., 48, 232-250, https://doi.org/ 10.1175/2008JAMC1923.1.

Locatelli, J. D., and P. V. Hobbs, 1974: Fall speeds and masses of solid precipitation particles. J. Geophys. Res., 79, 2185-2197, https://doi.org/10.1029/JC079i015p02185.

Magono, C., K. Kikuchi, T. Kimura, S. Tazawa, and T. Kasai, 1966: A study on the snowfall in the winter monsoon season in Hokkaido with special reference to low land snowfall. J. Fac. Sci. Hokkaido Univ. Ser. 7, 2, 287-308.

Markowski, P., and Y. Richardson, 2010: Mesoscale Meteorology in Midlatitudes. Wiley-Blackwell, 407 pp.

McMillen, J. D., and W. J. Steenburgh, 2015a: Impact of microphysics parameterizations on simulations of the 27 October
2010 Great Salt Lake-effect snowstorm. Wea. Forecasting, 30, 136-152, https://doi.org/10.1175/WAF-D-14-00060.1.

$\longrightarrow$, and - 2015b: Capabilities and limitations of convectionpermitting WRF simulations of lake-effect systems over the Great Salt Lake. Wea. Forecasting, 30, 1711-1731, https://doi.org/ 10.1175/WAF-D-15-0017.1.

Minder, J. R., T. W. Letcher, L. S. Campbell, P. V. Veals, and W. J. Steenburgh, 2015: The evolution of lake-effect convection during landfall and orographic uplift as observed by profiling radars. Mon. Wea. Rev., 143, 4422-4442, https://doi.org/ 10.1175/MWR-D-15-0117.1.

Miura, Y., 1986: Aspect ratios of longitudinal rolls and convection cells observed during cold air outbreaks. J. Atmos. Sci., 43, 26-39, https://doi.org/10.1175/1520-0469(1986)043<0026: AROLRA $>2.0 . C O ; 2$.

Murakami, M., T. L. Clark, and W. D. Hall, 1994: Numerical simulations of convective snow clouds over the Sea of Japan; Two-dimensional simulations of mixed layer development and convective snow cloud formation. J. Meteor. Soc. Japan, 72, 43-62, https://doi.org/10.2151/jmsj1965.72.1_43.

, Y. Yamada, T. Matsuo, K. Iwanami, J. D. Marwitz, and G. Gordon, 2003: The precipitation process in convective cells embedded in deep snow bands over the Sea of Japan. J. Meteor. Soc. Japan, 81, 515-531, https://doi.org/10.2151/jmsj.81.515.

Nagata, M., 1991: Further numerical study on the formation of the convergent cloud band over the Japan Sea in winter. J. Meteor. Soc. Japan, 69, 419-428, https://doi.org/10.2151/ jmsj1965.69.3_419.

Nakai, S., and T. Endoh, 1995: Observation of snowfall and airflow over a low mountain barrier. J. Meteor. Soc. Japan, 73, 183199, https://doi.org/10.2151/jmsj1965.73.2_183.

_- M. Maki, and T. Yagi, 1990: Doppler radar observation of orographic modification of snow clouds- A case of enhanced snowfall. Report of the National Research Institute for Earth Science and Disaster Prevention, 45, 1-16.

—, K. Iwanami, R. Misumi, S. Park, M. Shimizu, and T. Kobayashi, 2003: Relation between snow-cloud mode and snowfall distribution observed in central Niigata prefecture. Report of the National Research Institute for Earth Science and Disaster Prevention, 64, 9-17.

$-, \ldots,-\ldots, \ldots$, - and T. Kobayashi, 2005: A classification of snow clouds by Doppler radar observations at Nagaoka, Japan. SOLA, 1, 161-164, https://doi.org/10.2151/ sola.2005-042.

NCEP/NWS/NOAA/U.S. Department of Commerce, 2000: NCEP FNL Operational Model Global Tropospheric Analyses, continuing from July 1999. NCAR-UCAR Research Data Archive at Computational and Information Systems Laboratory, accessed 25 March 2017, https://doi.org/10.5065/ D6M043C6.

Niziol, T. A., 1987: Operational forecasting of lake effect snowfall in western and central New York. Wea. Forecasting, 2, 310-321, https://doi.org/10.1175/1520-0434(1987)002<0310: OFOLES $>2.0 . \mathrm{CO} ; 2$.

— W. R. Snyder, and J. S. Waldstreicher, 1995: Winter weather forecasting throughout the eastern United States. Part IV: Lake effect snow. Wea. Forecasting, 10, 61-77, https://doi.org/ 10.1175/1520-0434(1995)010<0061:WWFTTE >2.0.CO;2.

Notaro, M., V. Bennington, and S. Vavrus, 2015: Dynamically downscaled projections of lake-effect snow in the Great Lakes basin. J. Climate, 28, 1661-1684, https://doi.org/10.1175/JCLI-D-14-00467.1.

Ohigashi, T., and K. Tsuboki, 2007: Shift and intensification processes of the Japan-Sea polar-airmass convergence zone associated with 
the passage of a mid-tropospheric cold core. J. Meteor. Soc. Japan, 85, 633-662, https://doi.org/10.2151/jmsj.85.633.

Ohtake, H., M. Kawashima, and Y. Fujiyoshi, 2009: The formation mechanism of a thick cloud band over the northern part of the Sea of Japan during cold air outbreaks. J. Meteor. Soc. Japan, 87, 289-306, https://doi.org/10.2151/jmsj.87.289.

Reeves, H. D., and D. T. Dawson, 2013: The dependence of QPF on the choice of microphysical parameterization for lakeeffect snowstorms. J. Appl. Meteor. Climatol., 52, 363-377, https://doi.org/10.1175/JAMC-D-12-019.1.

Reinecke, P. A., and D. R. Durran, 2008: Estimating topographic blocking using a Froude number when the static stability is nonuniform. J. Atmos. Sci., 65, 1035-1048, https://doi.org/ 10.1175/2007JAS2100.1.

Rinehart, R. E., 1997: Radar for Meteorologists. 3rd ed. Rinehart Publications, 428 pp.

Saito, K., M. Murakami, T. Matsuo, and H. Mizuno, 1996: Sensitivity experiments on the orographic snowfall over the mountainous region of northern Japan. J. Meteor. Soc. Japan, 74, 797-813, https://doi.org/10.2151/jmsj1965.74.6_797.

Skamarock, W. C., and J. B. Klemp, 2008: A time-split nonhydrostatic atmospheric model for Weather Research and Forecasting applications. J. Comput. Phys., 227, 3465-3485, https://doi.org/10.1016/j.jcp.2007.01.037.

Steenburgh, J., 2014: Secrets of the Greatest Snow on Earth. Utah State University Press, 186 pp.

Steenburgh, W. J., and L. S. Campbell, 2017: The OWLeS IOP2b lake-effect snowstorm: Shoreline geometry and the mesoscale forcing of precipitation. Mon. Wea. Rev., 145, 2421-2436, https://doi.org/10.1175/MWR-D-16-0460.1.

Stoelinga, M. T., 2009: A users' guide to RIP version 4: A program for visualizing mesoscale model output. UCAR, accessed 22 September 2017, http://www2.mmm.ucar.edu/wrf/users/ docs/ripug.htm.
Tachibana, Y., 1995: A statistical study of the snowfall distribution on the Japan Sea side of Hokkaido and its relation to synopticscale and meso-scale environments. J. Meteor. Soc. Japan, $\mathbf{7 3}$, 697-715, https://doi.org/10.2151/jmsj1965.73.3_697.

Thompson, G., P. R. Field, R. M. Rasmussen, and W. D. Hall, 2008: Explicit forecasts of winter precipitation using an improved bulk microphysics scheme. Part II: Implementation of a new snow parameterization. Mon. Wea. Rev., 136, 5095-5115, https://doi.org/10.1175/2008MWR2387.1.

Tsuboki, K., Y. Fujiyoshi, and G. Wakahama, 1989: Doppler radar observation of convergence band cloud formed on the west coast of Hokkaido Island. II: Cold frontal type. J. Meteor. Soc. Japan, 67, 985-999, https://doi.org/10.2151/ jmsj1965.67.6_985.

Tsuchiya, K., and T. Fujita, 1967: A satellite meteorological study of evaporation and cloud formation over the western Pacific under the influence of the winter monsoon. J. Meteor. Soc. Japan, 45, 232-250, https://doi.org/10.2151/ jmsj1965.45.3_232.

Yamada, Y., M. Murakami, H. Mizuno, M. Maki, S. Nakai, and K. Iwanami, 2010: Kinematic and thermodynamical structures of longitudinal-mode snow bands over the Sea of Japan during cold-air outbreaks. Part I: Snow bands in large vertical shear environment in the band-transverse direction. J. Meteor. Soc. Japan, 88, 673-718, https://doi.org/10.2151/jmsj.2010-404.

Yamaguchi, S., O. Abe, S. Nakai, and A. Sato, 2011: Recent fluctuations of meteorological and snow conditions in Japanese mountains. Ann. Glaciol., 52, 209-215, https://doi.org/10.3189/ 172756411797252266.

Yoshihara, H., M. Kawashima, K. I. Arai, J. Inoue, and Y. Fujiyoshi, 2004: Doppler radar study on the successive development of snowbands at a convergence line near the coastal region of Hokuriku district. J. Meteor. Soc. Japan, $\mathbf{8 2}$, 1057-1079, https://doi.org/10.2151/jmsj.2004.1057. 